\title{
Managing Capital Market Frictions via Cost-Reduction Investments
}

\author{
Fehmi Tanrisever, ${ }^{a}$ Nitin Joglekar, ${ }^{b}$ Sinan Erzurumlu, ${ }^{c}$ Moren Lévesque ${ }^{d}$ \\ ${ }^{\mathbf{a}}$ Faculty of Business Administration, Bilkent University, 06800 Ankara, Turkey; ${ }^{\mathbf{b}}$ Questrom School of Business, Boston University, Boston, \\ Massachusetts 02215; ${ }^{\mathbf{c}}$ Olin School of Business, Babson College, Babson Park, Massachusetts 02457; d Schulich School of Business, York \\ University, Toronto, Ontario M3J 1P3, Canada \\ Contact: tanrisever@bilkent.edu.tr, (iD https://orcid.org/0000-0002-3921-3877 (FT); joglekar@bu.edu, \\ (iD) https://orcid.org/0000-0002-6478-337X (NJ); serzurumlu@babson.edu, (iD https://orcid.org/0000-0003-4226-3522 (SE); \\ mlevesque@schulich.yorku.ca (ML)
}

Received: March 6, 2018

Revised: December 28, 2018; April 16, 2019

Accepted: May 5, 2019

Published Online in Articles in Advance: March 13, 2020

https://doi.org/10.1287/msom.2019.0814

Copyright: ๑) 2020 INFORMS

\begin{abstract}
Problem definition: We examine how the presence of capital market frictions influences the decision to invest in production cost reduction and the resultant production volume. This investment can increase the firm's cash flow by increasing the profit margin, but it can also decrease the firm's risk-free cash reserves and thus affect its exposure to capital market frictions. Academic/practical relevance: Process improvement aimed at production cost reduction has generated myriad of theoretical questions about efficient investment options and capacity choices. From a managerial perspective, process improvement is a fundamental concern in operations strategy. Nevertheless, its analysis typically excludes financial constraints by assuming a perfect capital market. Methodology: We formulate a two-stage profit maximization model in which a capital-constrained firm commits to a cost-reduction investment in the first stage in anticipation of its production decision in the second stage of this two-stage decision process. The firm considers capital market frictions when making decisions at each stage, while considering uncertainty in demand for its offering and in reducing its unit production cost. Results: When a firm faces small initial capital and low preinvestment unit production costs, it can benefit from investing in production cost reduction in the presence of capital market frictions more so than in their absence. Moreover, uncertainty in the production cost reduction mitigates the impact of market frictions on the net benefit (i.e., additional profit), whereas demand uncertainty decreases the feasible parameter space, where investing in production cost reduction is optimal. Managerial implications: A firm's decision to invest in production cost reduction affects its operational and financial capabilities. Managers should thus consider this investment as an operational hedge not only against the uncertainty of matching supply and demand but also against exposure to capital market frictions and the resultant financial risk.
\end{abstract}

Supplemental Material: Online appendices A and B are available at https://doi.org/10.1287/msom.2019.0814 and online appendices C, D, and E are available at http://dx.doi.org/10.2139/ssrn.3370251.

Keywords: cost-reduction investment - operational hedging - capital market frictions - OM-finance interface

\section{Introduction}

Production process improvement aimed at cost reduction is a common management decision, which raises theoretical questions about the firm's efficient investment options and capacity choices (Balcer and Lippman 1984, Li and Rajagopalan 2008). From a management perspective, process improvement, particularly unit cost reduction in production, has been identified as "a fundamental concern in operations strategy" (Van Mieghem and Allon 2015, p. 402) and scholars often link the corresponding investment decisions with production quantity choices (e.g., Terwiesch and Bohn 2001, Kouvelis and Tian 2014). Moreover, work on production process improvement often assumes that a firm has sufficient resources to fund production, or that it can acquire these resources without any capital market frictions (e.g., bankruptcy costs, information asymmetry, transaction costs; Froot et al. 1993). Consequently, studies of production quantity decisions typically exclude financial constraints (e.g., Petruzzi and Dada 1999). But what happens if a manager facing capital market frictions invests in production cost reduction in anticipation of the production decision? We explore this question, which, thus far, has not been investigated.

Firms have invested to reduce production costs in various software, facility, or product update technologies, such as smart machines (e.g., facility machines fitted with sensors), electronic log and prognostics algorithms, automatic probing and inspection, multitasking, cutting and drilling, robotic automation, 3D sensing, and digital manufacturing (Gordon 2005). Furthermore, motivated by the recent developments in digital technologies, firms are expected to invest in smart 
manufacturing initiatives with an estimated \$115 billion mostly in asset utilization, throughput/efficiency, and quality assurance for 2018 (IDC 2018). In particular, businesses that invest in technologies to reduce operating costs gain significant advantages over their competitors, particularly in manufacturing, because acquiring and processing production data through investment in production capability have emerged as key factors in determining competitive standing (e.g., Brooks 2017). Therefore, firms consider costreducing process investments to generate operating cost advantages related to their size or manufacturing volume.

In our fieldwork, we observed a similar strategy whereby firms consider production process improvement as a key operational concern. For instance, managers at Faradox Energy Storage, an Austin, Texasbased high-tech startup, acknowledged that although the cost-reducing process of research and development was expensive with highly uncertain returns, it was crucial for survival and long-term growth in a highly uncertain market. Similarly, the founder of Bigfoot Networks (bought by Qualcomm in 2011), a startup that provided microchips to reduce online game lag and latency, had expressed his commitment to reducing unit manufacturing costs, even though his two major concerns were product demand and access to capital. Bigfoot Networks first had to decide whether to invest in a technology that could reduce its unit production cost with uncertain performance results, followed by a production decision with uncertain future demand for its microchips. Bigfoot Networks, a startup also short on capital, had relied on external funds to run the business. Its founder knew that he had to make good use of existing funds and if the cost-reduction investment proved successful, he could access more funds in the future and possibly at a lower cost.

From this anecdotal evidence, we can infer the key trade-off that firms face when contemplating production process improvements: Investing to reduce the unit production cost will enhance the net unit profit margin, which can subsequently decrease a firm's financial risk, but it will also reduce the firm's risk-free capital, thus increasing its financial risk. Given these two counteracting effects, firms must consider cost-reduction investment as an operational hedge against both the uncertainty of matching their supply and demand, as well as their exposure to capital market frictions. To better understand the impact of the cost-reduction investment decision on the net benefit—additional profit—we must formalize two related effects. The first is a positive operational effect associated with an increase in the firm's profit margin because of production cost reduction. The second effect, which can be positive or negative, is a capital market friction effect (hereafter friction effect), which captures the change in financing costs due to these frictions when a firm must rely on external funds for production. Whereas a net increase in the cost of external funds (i.e., a negative friction effect) will reduce the firm's net benefit from investing, a net reduction in these external funds' costs (i.e., a positive friction effect) will increase that benefit.

Although the operational hedging literature (e.g., Van Mieghem 2003, Weiss and Maher 2009) has investigated the abovementioned operational effect (i.e., increases in profit margins due to production cost reduction), few scholars have explored the friction effect associated with cost-reduction investment decisions amid capital market frictions; notable exceptions are Boyabatli and Toktay (2011) and Iancu et al. (2016) in the context of flexible capacity choice. We thus extend this emerging literature by asking: (1) Under what conditions should a firm invest in reducing its unit production cost in the presence of capital market frictions? (2) How will the level of capital market frictions affect the net benefit from cost reduction investments? (3) How will the level of demand uncertainty affect the cost-reduction-investment decision in the presence of capital market frictions? And (4) How will the uncertainty of the unit production cost reduction per dollar invested (hereafter production-cost-reduction uncertainty) condition the capital market frictions' impact? We explore these questions by formulating a twostage profit-maximization model, where a capitalconstrained firm facing capital market frictions must first decide whether to make a production-costreduction investment in anticipation of a production decision.

By exploring ex ante cost-reduction investment decisions, while factoring in capital market frictions, this article contributes to the literature in several ways. First, we show that, through a combination of analytical and numerical studies, a threshold investment policy is optimal, and the investment threshold increases with the level of capital market frictions. Next, we separate the cost-reduction investment's operational effect on firm profit from the friction effect, and we identify conditions under which the friction effect is positive. In other words, we propose that the cost of using external funds decreases because of a production-cost-reduction investment when the firm's initial capital is small, the unit production cost is low, and its cost reduction per dollar invested is large. We also identify the conditions under which a firm can achieve greater net benefits (i.e., realize more additional profits) from a cost-reduction investment in the presence of capital market frictions than in their absence (i.e., a perfect capital market), again due to a possible positive friction effect, resulting in reduced costs of external funds. Extant operational hedging literature has not explored whether this positive 
friction effect exists and how it interacts with the operating characteristics of a firm. We numerically show that when the friction effect is positive, a firm with more initial capital benefits less from investing than a firm with less initial capital, because by lowering the friction effect, more initial capital can substitute the aim of the investment, which is to mitigate the firm's exposure to capital market frictions.

Furthermore, our exploration of uncertainty in production cost reduction, in which the unit production cost reduction per dollar invested is a random variable, suggests that this uncertainty can mitigate the impact of capital market frictions on a firm's net benefit from investing in production cost reductions. Specifically, if the friction effect is positive and thus eases the firm's access to external funds (by reducing their costs), then the friction effect is smaller with more productioncost-reduction uncertainty than with less such uncertainty. However, if the friction effect is negative and thus worsens the firm's access to external funds (by increasing their costs), then as long as the initial unit production cost is not too steep, the friction effect is smaller in its absolute value-and thus less negative-with more production-cost-reduction uncertainty than with less such uncertainty. We also identify conditions under which introducing capital market frictions produces a larger net benefit from investing in production cost reduction with more uncertainty in that reduction than with less uncertainty. Thus, we offer new insights into the interaction of production-cost-reduction uncertainty and capital market frictions, insights that complement the work of Boyabatli and Toktay (2011) and Iancu et al. (2016), who have focused instead on demand uncertainty and operational flexibility in the presence of such frictions.

\section{Literature}

We posit that a firm's decision to invest in reducing its unit production costs can serve as a two-pronged operational hedge against (1) matching supply and demand, and (2) managing exposure to capital market frictions. Therefore, we divide the relevant literature into four streams (see Table 1): articles that discuss operating decisions in perfect (i.e., no frictions) and imperfect (i.e., with frictions) capital markets, and operating decisions with and without operational hedging.

The left column of Table 1 represents the relevant literature under perfect capital markets in which a firm can make separate operational and financial decisions. The decision to invest in either capacity growth or production cost reduction in these settings often leads to a threshold policy based on operating choices (see, e.g., Balcer and Lippman 1984, Rajagopalan 1998, Carrillo and Gaimon 2004) in the absence of capital market frictions (Table 1, top-left quadrant). In the operational hedging literature, riskmitigating operational decisions are explored in perfect capital markets (Table 1, bottom-left quadrant). This literature thus abstracts from the financial implications of operational hedging decisions, including a firm's ability to access capital and the resultant cost of external funds, because capital markets are assumed to be perfect (Huchzermeier and Cohen 1996, Boyabatli and Toktay 2004, Chod et al. 2010, Dong et al. 2014). In contrast to the literature on operational decisions in perfect capital markets (Table 1, left column), we examine the conditions under which investing in production cost reduction can create value in the presence of capital market frictions. Our analysis herein also relates to the work of Tanrisever et al. (2012), which shows that production process investment should be coupled with production decisions in the presence of survival constraints and fixed financing costs. Although our investment type is similar to that of Tanrisever et al. (2012), our financial setup and its implications differ. We endogenize the financial constraints and explain how production-cost-reduction investment can affect the cost of external funds and can create a hedge against a firm's exposure to capital market frictions.

The right column of Table 1 shows studies that address the imperfect capital market condition, wherein operational and financial decisions are jointly considered by factoring in various capital market frictions. The top-right quadrant illustrates these decisions without considering the option of operational

Table 1. Classification of Relevant Literature

\begin{tabular}{lll}
\hline & \multicolumn{1}{c}{ Perfect capital market } & \multicolumn{1}{c}{ Imperfect capital market } \\
\hline $\begin{array}{c}\text { Operational decisions } \\
\text { without hedging }\end{array}$ & $\begin{array}{l}\text { Balcer and Lippman 1984, } \\
\text { Rajagopalan 1998, } \\
\text { Carrillo and Gaimon 2004 }\end{array}$ & $\begin{array}{l}\text { Xu and Birge 2006, Dada and Hu 2008, } \\
\text { Babich 2010, Kouvelis and Zhao 2011, } \\
\text { Luo and Shang 2014, Tanrisever et al. 2015, } \\
\text { Alan and Gaur 2018, Tunca and Zhu 2018, } \\
\text { Reindorp et al. 2018, Yang and Birge 2018 }\end{array}$ \\
$\begin{array}{c}\text { Operational decisions } \\
\text { with hedging }\end{array}$ & $\begin{array}{l}\text { Huchzermeier and Cohen 1996, } \\
\text { Van Mieghem 2003, } \\
\text { Boyabatli and Toktay 2004, } \\
\text { Weiss and Maher 2009, Chod etal. 2010, } \\
\text { Tanrisever et al. 2012, Dong et al. 2014 }\end{array}$ & $\begin{array}{l}\text { Iancu et al. 2016 } \\
\text { (This article fits here) }\end{array}$ \\
\hline
\end{tabular}


hedging. Kouvelis and Zhao (2011) explore optimal contracting for a supplier with a retailer in a newsvendor setting in the presence of bankruptcy costs. Similarly, Alan and Gaur (2018) examine the effect of bankruptcy costs and information asymmetry on the firm's operating plans under asset-based lending. Scholars also consider the role of trade credit (Luo and Shang 2014, Yang and Birge 2018) and supply chain finance (Tanrisever et al. 2015, Reindorp et al. 2018, Tunca and Zhu 2018) in the supply chain contracting context. In addition, $\mathrm{Xu}$ and Birge (2006) and Dada and $\mathrm{Hu}$ (2008) provide formal newsvendor models to account for a bank-firm interaction, whereas Babich (2010) considers financial subsidies from manufacturers without exploring the hedging option. Scholars who consider underproduction (e.g., Kouvelis and Zhao 2011) show that capital market frictions lower the optimal critical fractile.

The literature on operational decisions with both hedging and capital market frictions (Table 1, lowerright quadrant) explores how the operational hedging decision is conditioned under these frictions, if present. More recently, Iancu et al. (2016) examine the value of operating flexibility in the presence of capital market frictions and debt covenants. They find that by providing risk-shifting incentives, operating flexibility can substantially increase borrowing costs. They also argue that proper debt covenants can be designed to mitigate the impact of capital market frictions and restore firm value. Although we consider neither riskshifting nor agency problems, we explore an alternative that complements investment choice and operating flexibility. We identify conditions when productioncost-reduction investment can increase or decrease the cost of external funds in the presence of bankruptcy costs.

A comparison of our setting with that of Boyabatli and Toktay (2011) is also instructive. They investigate a firm's technology-selection decision with endogenous interest rates (determined by the lending bank) and show how capital market frictions condition this decision. In particular, these frictions can alter the capacity-investment decisions to move from a dedicated to a flexible technology, owing to the interplay between the financial-pooling benefits of both technologies and the capacity-pooling benefit of only the flexible technology. In addition to considering the endogenous cost of borrowing, our model also explores investment in production cost reduction where (1) the reduction per dollar invested can be uncertain and (2) the firm can borrow to fund production in anticipation of uncertain demand. We can then characterize when the cost of using external funds increases or decreases based on the resultant operating conditions following the production-cost-reduction investment. We also characterize the conditions under which greater capital market frictions increase the net benefit from investing in production cost reduction, and how cost-reduction uncertainty might affect this relationship.

\section{Model and Structural Properties}

We formulate a two-stage decision-theoretic model with three crucial time points. Figure 1 summarizes the time line of events and decisions at $t \in\{1,2,3\}$. Specifically, at $t=1$ the firm possesses initial capital $y_{1}$, including cash, cash equivalents and fixed assets that can be used as risk-free borrowing collateral. At $t=1$ the firm must decide whether to invest an indivisible amount $A$ to reduce its unit production cost. This production-cost-reduction investment could require the firm to build a pilot plant or purchase new equipment to streamline the production process and reduce the unit production cost. This investment consumes a portion of the firm's initial capital during the investment stage (stage 1) and increases the need for external funds for the production stage (stage 2). Investing in production cost reduction also generates returns at the end of stage 1 by (linearly) reducing the firm's unit production cost $c_{1}$ for stage 2 (e.g., Gupta and Loulou 1998, Tanrisever et al. 2012). Formally, $c_{2}=c_{1}-\beta A$, where $c_{2}\left(<c_{1}\right)$ is the reduced (positive) unit production cost for the production stage. The parameter $\beta\left(\in\left[0, \frac{c_{1}}{A}\right]\right)$ is the unit production cost reduction per dollar invested. We later transform this marginal return into a random variable to examine the impact of cost-reduction uncertainty on this decision problem.

At $t=2$, the production stage begins. If the firm invests in production cost reduction, it is left with only the remaining capital, $y_{2}=y_{1}-A \geq 0$; if the firm does not invest, it holds $y_{2}=y_{1}$. At this time point, the firm must also select a production quantity $q$, while considering a random demand $\xi$, where $q$ is based on the unit production cost $c_{2}$ and remaining capital $y_{2}$. Unless otherwise stated, we assume that regardless of the investment decision, initial capital is insufficient for the production stage, which is common for capitalpoor startups (e.g., Brealey et al. 2016). The firm thus requires external funds amounting to $c_{2} q-y_{2}$ to finance its production $q$. We assume that the firm and the bank share the same information about demand $\xi$ and unit production $\cos t c_{2}$.

Given the firm's investment and production decisions, at $t=2$, the bank issues a loan with a certain face value, $F(q)$, which depends on the loan's principal amount, $L(q)=c_{2} q-y_{2}$, bankruptcy risk, and capital market frictions, such as bankruptcy costs. Bankruptcy costs may include direct costs, such as administrative and legal fees, and indirect costs, such as a loss of revenues, if the firm's operations are inhibited under financial distress (Brander and Lewis 1988). 
Figure 1. Timeline of Events and Decisions

\section{Firm observes}

(1) initial unit production $\cos t c_{1}$

(2) initial capital $y_{1}$

(3) unit production cost reduction per dollar invested $\beta$

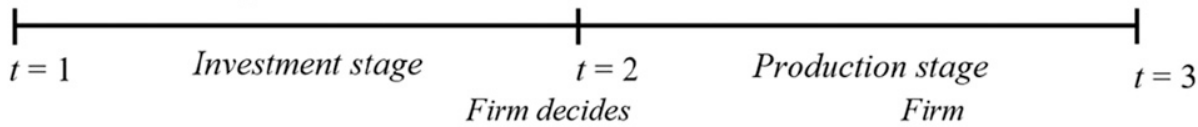

Firm decides

(1) whether to invest amount $A$
Firm \& bank observe

(1) reduced unit production $\operatorname{cost} c_{2}$

(2) remaining capital $y_{2}$
Firm \& bank observe

(1) realized demand $\xi$

(2) revenue $p \min (q, \xi)$
(1) production quantity $q$

(2) loan's principal amount $L(q)$

Bank decides

(1) face value $F(q)$ of the loan
(1) pays its debt if $F(q) \leq p \min (q, \xi)$ or

(2) goes bankrupt if $F(q)>p \min (q, \xi)$ and bank recovers $[1-\gamma] p \min (q, \xi)$
In the literature, these costs are typically modeled either as a fixed cost (e.g., Blum 2002) or as a fraction of the firm's residual asset value (e.g., Leland 1994, Leland and Toft 1996, Lai et al. 2009). More recently, Kouvelis and Zhao $(2011,2015)$ include both fixed and proportional bankruptcy costs in their models. For expositional clarity, we model bankruptcy costs as a proportion of the firm's revenue, where the revenue amounts to $p \min (q, \xi)$ with $p$ signifying the unit sales price and, as defined above, $\xi$ representing the uncertain demand. We refer to $\gamma \in[0,1]$ as the capital-market-friction proportion, that is, the proportion of revenues lost in the bankruptcy process.

At the loan maturity point $t=3$, the uncertain demand $\xi$ and revenue are realized. If the firm generates enough revenue, then the bank recovers the loan's full face value $F(q)$. Otherwise, the firm goes bankrupt and the bank receives $p \min (q, \xi)$ minus the bankruptcy $\operatorname{cost} \gamma p \min (q, \xi)$. The bank's cash flow, denoted by $\chi$, is thus

$$
\chi=\left\{\begin{array}{lll}
F(q) & \text { if } & F(q) \leq p \min (q, \xi) \\
(1-\gamma) p \min (q, \xi) & \text { if } & F(q)>p \min (q, \xi)
\end{array}\right.
$$

Without loss of generality, we assume that the riskfree rate is zero. Accordingly, in a competitive financial market, the loan is priced, meaning that $F(q)$ is determined such that the expected return to the bank equals zero (e.g., $\mathrm{Xu}$ and Birge 2006). Thus,

$$
E_{\xi}[\chi]=L(q)
$$

or, using an indicator function $I_{\{.\}}$,

$$
\begin{aligned}
& E_{\xi}\{\min [p \min (q, \xi), F(q)]\} \\
& -E_{\xi}\left\{\gamma p \min (q, \xi) I_{\{p \min (q, \xi) \leq F(q)\}}\right\}=L(q) .
\end{aligned}
$$

Similarly, the firm's net cash flow at $t=3$ is

$$
p \min (q, \xi)+L(q)-c_{2} q-\min [p \min (q, \xi), F(q)]-A .
$$

If the firm generates enough revenue and stays afloat, it receives the revenue plus loan principal and pays the production costs and loan's face value. If the firm declares bankruptcy, then the bank takes all its revenue. The firm's net cash flow is thus given by the cash flow at $t=3$ net the investment cost.

From applying the expectation operator and using Equation (2), the firm's profit-maximization problem at the start of the production stage, after having invested amount $A$ during that stage, is

$$
\begin{aligned}
\pi_{A}= & \max _{q}\left\{E_{\xi}[p \min (q, \xi)]-c_{2} q\right. \\
& -E_{\xi}\left[\gamma p \min (q, \xi) I_{\{p \min (q, \xi) \leq F(q)\}]\}-A .}\right.
\end{aligned}
$$

The term $E_{\xi}\left[\gamma p \min (q, \xi) I_{\{p \min (q, \xi) \leq F(q)\}}\right]$ represents the expected bankruptcy cost that we also denote by $K(q)$; for notational brevity we suppress the dependence of $K$ on all other variables except production quantity $q$. Prior to characterizing the properties of $K(q)$ so as to analyze the equilibrium production quantity, we present a series of assumptions to construct the baseline model. Specifically,

Assumption 1. Demand $\xi$ follows a uniform probability distribution with support $[0, a]$.

Assumption 2. Maximum revenue exceeds the loan's face value adjusted by the capital-market-friction proportion, ap $>(1+\gamma) F(q)$.

Assumption 3. The firm receives a loan to produce quantity $q$ only if $q p>F(q)$.

We follow the lead of Marschak et al. (2015) for Assumption 1 because doing so enables analytical tractability. Our main insights hold under various probability distribution functions, but analytical tractability is greatly curtailed (e.g., we numerically confirmed the robustness of our results under a normal distribution, as detailed in Online Appendix B.3). Assumption 2 states that the maximum possible revenues ap will be enough to pay the loan's face value adjusted by the capital-market-friction proportion. When $\gamma=0$, expectedly the maximum revenue should be greater than the loan's face value because otherwise the firm will default and thus the bank will not issue 
the loan. In the presence of capital market frictions, the bank anticipates the bankruptcy costs and demands a tighter condition to issue a loan as given in Assumption 2. Similarly, Assumption 3 stipulates that, given production quantity $q$, the bank will provide a loan only if the revenue when all goods are sold, $q p$, is sufficient to recover the loan's face value. Assumptions 2 and 3 are both weak and rule out cases where issuing loans would be inefficient.

\subsection{Equilibrium Production Decision}

Under the above three assumptions, we derive the equilibrium profit and production quantity. As a first step, we establish that the expected bankruptcy cost $K(q)$ is positive (as is expected) and is an increasing convex function of the production quantity $q$. Formally (all proofs appear in Online Appendix A),

Lemma 1. Expected bankruptcy cost is characterized as $K(q)>0, \partial K(q) / \partial q>0$ and $\partial^{2} K(q) / \partial q^{2}>0$.

The expected bankruptcy cost increases (at an increasing rate) in $q$ because, as the production quantity increases, so do the required loan amount and exposure to capital market frictions. The convexity of $K(q)$ leads to a unique equilibrium production quantity that maximizes the firm's (expected) profit. Formally,

Proposition 1. When a firm chooses to invest amount $A$ to reduce its unit production cost, the equilibrium production quantity $q_{A}$ and the loan's face value $F_{A}$ are derived by simultaneously solving

$$
\begin{aligned}
& p\left[1-\frac{q_{A}}{a}\right]-\left[c_{1}-\beta A\right]=\frac{\gamma}{\frac{a p}{F_{A}}-[1+\gamma]}\left[c_{1}-\beta A\right], \text { and } \\
& E_{\xi}\left[\min \left(p \min \left(q_{A}, \xi\right), F_{A}\right)\right] \\
& -E_{\xi}\left[\gamma p \min \left(q_{A}, \xi\right) I_{\left\{p \min \left(q_{A}, \xi\right) \leq F_{A}\right\}}\right]=c_{2} q_{A}-y_{2} .
\end{aligned}
$$

Proposition 1 characterizes the equilibrium production quantity $q_{A}$ when the firm invests amount $A$, in which case the expected profit is $\pi_{A}=E_{\xi}\left[p \max \left(q_{A}, \xi\right)\right]-$ $c_{2} q_{A}-K\left(q_{A}\right)-A$. When the capital market is frictionfree $(\gamma=0)$, Equation (5) describes a classic newsvendor solution, yet from Equation (6) the firm still borrows and pays interest. When the firm does not invest, Proposition 1 still applies and the equilibrium production quantity $q_{0}$ and loan's face value $F_{0}$ are derived by setting $A=0$ in these equations.

Investing in production cost reduction has two crucial effects on the production quantity: (1) a direct operational effect captured by the reduction in the unit production cost (from $c_{1}$ to $c_{1}-\beta A=c_{2}$ ) and (2) an indirect friction effect which reflects the impact of capital market frictions. Next, we describe the equilibrium critical fractile, denoted $C F\left(q_{A}\right)$, which formalizes these two effects on the production quantity.
Corollary 1. When a firm invests amount $A$ to reduce its unit production cost, the critical fractile that characterizes the equilibrium production quantity is

$$
\begin{aligned}
C F\left(q_{A}\right) & =\frac{p-\left[1+w\left(q_{A}\right)\right]\left[c_{1}-\beta A\right]}{p}, \text { where } \\
w\left(q_{A}\right) & =\frac{\gamma}{\frac{a p}{F_{A}}-[1+\gamma]} .
\end{aligned}
$$

In Corollary 1 , we note that $w\left(q_{A}\right)$ reflects the reduction in the critical fractile, and hence a reduction in the production amount, due to capital market frictions. This quantity monotonically decreases with increases in these frictions and becomes zero when the capital market is perfect (i.e., $\gamma=0$ ). If the net effect of investing results in an adjusted unit cost below $c_{1}$, that is, if $\left[1+w\left(q_{A}\right)\right]\left[c_{1}-\beta A\right]<c_{1}$, then the equilibrium production quantity $q_{A}$ exceeds $q_{0}$.

\subsection{Impact of the Investment Decision: Operational and Friction Effects}

We have so far examined the equilibrium production quantity decision (at $t=2)$. We next explore the impact of the investment decision (at $t=1$ ) on the firm's profitability and financing costs in equilibrium. For this purpose, we return to Proposition 1 and define two key metrics that characterize the equilibrium production decision when the firm invests in production cost reduction. The left-hand side of Equation (5) represents the marginal rate of return or $\operatorname{MRR}(q \mid$ investment $)=p\left[1-\frac{q}{a}\right]-c_{2}$ for a given production quantity $q$. The right-hand side of Equation (5) represents the marginal cost of (using) external funds; that is,

$$
\operatorname{MCE}(q \mid \text { investment })=\frac{\gamma}{\frac{a p}{F_{A}(q)}-[1+\gamma]} c_{2},
$$

where $F_{A}(q)$ is the loan's face value for a given $q$ (and thus $\left.F_{A}=F_{A}\left(q_{A}\right)\right)$. The firm's equilibrium production quantity is thus achieved when the marginal rate of return on each unit produced equals the marginal cost of external funds required to produce that unit.

For a firm that does not invest, the terms are respectively $\operatorname{MRR}(q \mid$ no investment $)=p\left[1-\frac{q}{a}\right]-c_{1}$ and

$$
\operatorname{MCE}(q \mid \text { no investment })=\frac{\gamma}{\frac{a p}{F_{0}(q)}-[1+\gamma]} c_{1},
$$

where the unit production cost and initial capital remain at $c_{1}$ and $y_{1}$, respectively, and the loan's face value is calculated accordingly. Recall that when the firm does not invest, the equilibrium production quantity is $q_{0}$ and for a given $q$, we denote the loan's face value by $F_{0}(q)$ (thus $F_{0}=F_{0}\left(q_{0}\right)$ ). Lemma 2 describes the behavior of the marginal cost of external funds as expressed by the two abovementioned MCE curves.

Lemma 2. $\operatorname{MCE}(q \mid$ no investment $)$ and $\operatorname{MCE}(q \mid$ investment $)$ curves are convex and increasing in $q$. 
Figure 2. (Color online) Equilibrium $M C E$ and $M R R$ Curves (No Investment, with Capital Market Frictions)

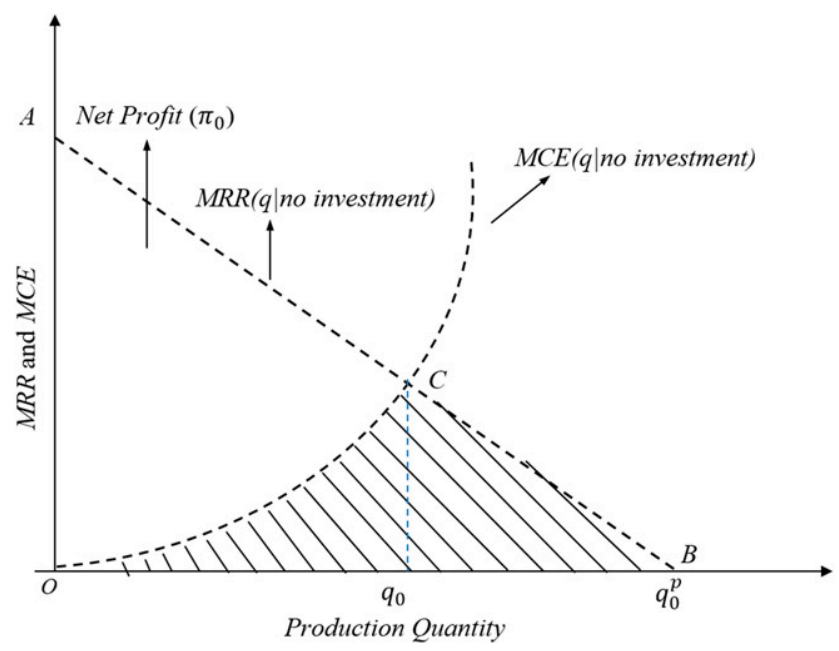

Figure 2 illustrates the equilibrium production quantity decisions and profits when the firm does not invest. The region below the $\operatorname{MRR}(q \mid$ no investment $)$ curve, Area $(\mathrm{OAB})$, represents firm profit under a perfect capital market, where $q_{0}^{p}$ is the equilibrium production quantity. In the presence of capital market frictions, the firm must pay a cost for using external funds, as shown in the upward sloping $M C E(q \mid$ no investment $)$ curve; the shaded region, Area(OCB), represents the cost of such funds. Consistent with the finance literature for a perfect capital market (i.e., when $\gamma=0)$, the $M C E(q \mid$ no investment) curve is flat (i.e., superposes the $x$ axis) with no cost for using external funds (even though the firm borrows and pays interest). The firm's net profit in the presence of capital market frictions therefore depends on the following two components:

i. $R_{1}$ (no investment): the operational profit equals to Area $(\mathrm{OAB})$ and

ii. $R_{2}$ (no investment): the cost of external funds equals to Area(OCB).

The firm's net profit is given by $\pi_{0}=$ Area $(O A B)-$ Area(OCB).

When a production-cost-reduction investment is made, it affects both the operational profit and the cost of using external funds. In other words, both the $M C E$ and MRR curves shift, which changes the sizes of Area $(\mathrm{OAB})$ and Area(OCB). Intuitively, because investing enhances the firm's operational capabilities, Area $(\mathrm{OAB})$ always increases. However, the impact of investing on Area(OCB) is nontrivial. On the one hand, investing depletes cash reserves (prior to production) and potentially increases production quantity, which requires the firm to seek additional external funds, and thus may expand Area(OCB). On the other hand, investing can increase future cash flows, which reduces financial risk and produces a flatter MCE curve, and may shrink Area(OCB).
Figure 3. (Color online) Change in MRR and MCE Curves Following an Investment Decision (with a Clockwise Shift in the MCE Curve)

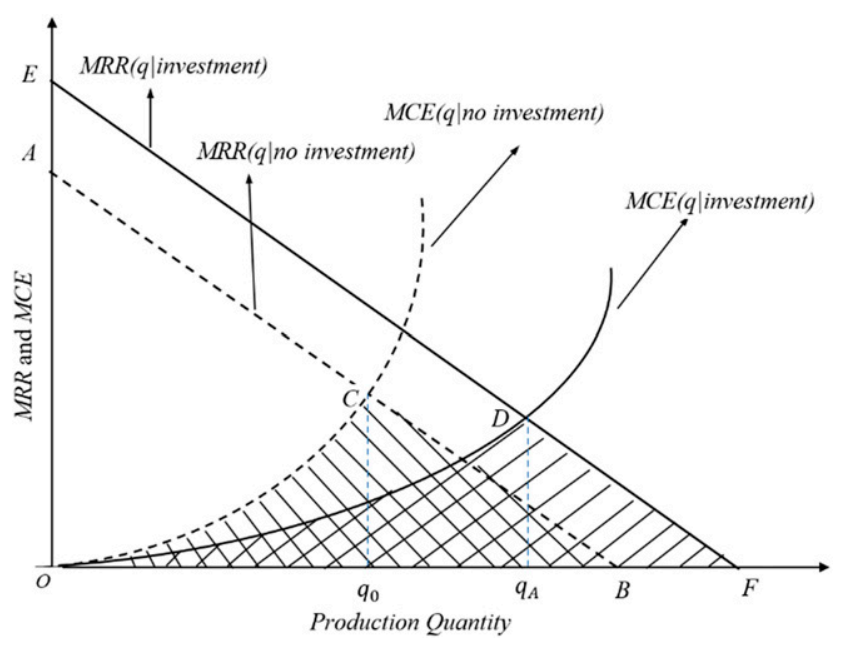

Figure 3 illustrates the change in the cost of external funds after the firm invests in reducing the unit production cost for a scenario where the marginal cost of external funds (MCE curve) presents a clockwise shift. (We omit the counterclockwise shift for brevity.)

It therefore follows that when the firm invests, the marginal rate of return (MRR) curve shifts upward and in this particular case, the marginal cost of external funds (MCE) curve shifts to the right. The two regions described above thus become

i. $R_{1}$ (investment): the operational profit equals to Area(OEF) and

ii. $R_{2}$ (investment): the cost of external funds = Area(ODF).

The firm's net profit after investing is given by $\pi_{\mathrm{A}}=$ Area $(\mathrm{OEF})-$ Area $(\mathrm{ODF})-\mathrm{A}$. The net benefit from investing (i.e., additional profit from investing) thus equals

$$
\begin{aligned}
\Pi= & \pi_{\mathrm{A}}-\pi_{0}=[\operatorname{Area}(\mathrm{OEF})-\operatorname{Area}(\mathrm{OAB})] \\
& +[\text { Area }(\mathrm{OCB})-\operatorname{Area}(\mathrm{ODF})]-A,
\end{aligned}
$$

and a firm should invest amount $A$ to reduce the unit production cost if and only if $\Pi>0$. Because this benefit $\Pi$ is driven by a change in operational capabilities and by the cost of external funds, it comprises the summation of two key effects:

1. an operational effect, $\Delta R_{1}=\operatorname{Area}(\mathrm{OEF})-\operatorname{Area}(\mathrm{OAB})$, which represents a purely operational impact from the production-cost-reduction investment on the firm's profit, and is independent of capital market frictions $(\gamma)$; and

2. a friction effect, $\Delta R_{2}=\operatorname{Area}(\mathrm{OCB})-\operatorname{Area}(\mathrm{ODF})$, which represents the change in the cost of using external funds and is thus purely driven by capital market frictions. 
That is, $\Pi=\Delta R_{1}+\Delta R_{2}-A$. We first observe that because only the friction effect depends on $\gamma$, examining the impact of capital market frictions on the net benefit from investing is identical to examining this impact on the friction effect; in other words, $\partial \Pi / \partial \gamma=$ $\partial \Delta R_{2} / \partial \gamma$. The next two propositions explicitly express the operational effect and the friction effect, with Proposition 2 first characterizing the operational effect.

Proposition 2. The operational effect $\Delta R_{1}$ is positive and equals $\frac{a \beta A\left(2 p-2 c_{1}+\beta A\right)}{2 p}$.

We observe that the operational effect is nonnegative because the firm's profit increases when the unit production cost is reduced (owing to the production-costreduction investment) and the unit price is fixed. Further, because the operational effect captures the investment benefits in a perfect capital market, initial capital $y_{1}$ does not affect the operational effect, as predicted by the Modigliani-Miller (MM) theorem (Modigliani and Miller 1958). Regarding the initial unit $\operatorname{cost} c_{1}$, we find that the operational effect is decreasing in $c_{1}$. As Figure 3 illustrates, investing in cost reduction is also accompanied by a friction effect $\Delta R_{2}$, which is either positive or negative, and can thus counter or complement the operational effect. Proposition 3 characterizes the friction effect.

Proposition 3. The friction effect $\Delta R_{2}$ equals

$$
\begin{aligned}
& \int_{q_{0}}^{a \frac{p-c_{1}}{p}}\left(p\left(1-\frac{q}{a}\right)-c_{1}\right) d q-\int_{q_{A}}^{a \frac{p-c_{2}}{p}}\left(p\left(1-\frac{q}{a}\right)-c_{2}\right) d q \\
& \quad+\int_{0}^{q_{0}} \frac{\gamma}{\frac{a p}{F_{0}(q)}-(1+\gamma)} c_{1} d q-\int_{0}^{q_{A}} \frac{\gamma}{\frac{a p}{F_{A}(q)}-(1+\gamma)} c_{2} d q,
\end{aligned}
$$

and a threshold $\hat{\beta}\left(<\frac{c_{1}}{A}\right)$ exists (i.e., the largest $\beta$ for which Equation (8) equals zero) where $\Delta R_{2}>0$ for $\beta>\hat{\beta}$.

A positive friction effect suggests that if the firm invests to reduce its unit production cost, that investment can reduce the cost of external funds and thus hedge against the firm's exposure to capital market frictions. A production-cost-reduction investment can thus shape the firm's financial risk, and hence influence the marginal cost of external funds,

$$
\operatorname{MCE}(q \mid \text { investment })=\left[\frac{\gamma}{\frac{a p}{F_{A}(q)}-(1+\gamma)}\right]\left[c_{1}-\beta A\right]
$$

in two ways: it increases financial risk by reducing the firm's risk-free cash reserves, but reducing the unit production cost also enhances the firm's profit margin and cash flow, thereby reducing its risk. When the second effect dominates, we observe a positive friction effect, which results in a reduced cost of external funds. Investing therefore brings two reinforcing effects: (1) it increases the firm's profit margin by reducing its unit production cost; and (2) it reduces the cost of external funds. The possibility of a positive friction effect leads to an even more striking result.

Proposition 4. If the friction effect $\Delta R_{2}$ is positive, then the firm achieves greater net benefits from a production-costreduction investment in the presence of capital market frictions than in their absence; that is, $\Pi(\gamma>0)>\Pi(\gamma=0)$.

It follows from Propositions 3 and 4 that if the unit production cost reduction per dollar invested is sufficiently high (i.e., $\beta>\hat{\beta}$ ), firms that face high costs for using external funds can benefit more from investing relative to firms that face no such cost, because investing can simultaneously and significantly reduce the cost of those external funds; we also observe that the friction effect can be nonmonotone in $\beta$ (e.g., as discussed in Online Appendix B.1). The drivers of this result are consistent with underinvestment findings from the finance literature (e.g., Froot et al. 1993), where $\pi_{A}(\gamma>0)<\pi_{A}(\gamma=0)$. Online Appendix C offers a detailed discussion of the subeffects (owing to either underproduction or direct financing costs) that drive the friction effect.

Furthermore, we examine the impact of the initial capital $\left(y_{1}\right)$ and initial unit cost $\left(c_{1}\right)$ on the friction effect. Intuitively, $y_{1}$ and $c_{1}$ condition the firm's exposure to capital market frictions, and hence affect both the friction effect and the firm's benefit from investing.

Proposition 5. If $c_{1} q_{0}<c_{2} q_{\mathrm{A}}+A$ such that investing increases the firm's financial needs, then $y_{1}$ and $c_{1}$ affect the friction effect $\left(\Delta R_{2}\right)$ as follows:

i. If $y_{1}>c_{2} q_{\mathrm{A}}+A$ or $c_{1}>p+\beta A$, then $\Delta R_{2}=0$.

ii. If $c_{1} q_{0}<y_{1}<c_{2} q_{\mathrm{A}}+A$ and $c_{1}<p+\beta A$, then $\Delta R_{2}<0$.

iii. If $y_{1}<c_{1} q_{0}$ and

a. $p<c_{1}<p+\beta A$, then $\Delta R_{2}<0$;

b. $c_{1}<p$ and $\beta>\hat{\beta}$, then $\Delta R_{2}>0$.

From Proposition 5.i, if the initial capital is enough for production, even after investing, then the friction effect is zero, because the firm requires no external funds. Similarly, if the initial unit cost exceeds $p+\beta A$, then even after investing to reduce the unit cost, the profit margin is still negative, which yields a production quantity and a friction effect equal to zero. However, if the initial capital is sufficient to finance production with no investment, but insufficient when an investment is made (Proposition 5.ii), then $\Delta R_{2}<0$ provided that the firm can earn a positive margin at least after investing (i.e., $c_{1}<p+\beta A$ ). This is because the firm only uses external funds when investing. Hence, investing always increases the cost of using external funds, resulting in a negative friction effect. But if the initial capital is sufficiently low (Proposition 5.iii) for the firm to require external funds, whether or not it invests in cost reduction, then the 
friction effect could be positive. Indeed, if the ex ante need for external funds is sufficiently high ( $y_{1}$ is low) and investing significantly increases future cash flows $\left(c_{1}\right.$ is low and $\beta>\hat{\beta}$ ), then after investing the $M C E$ curve substantially shifts to the right, lowering the cost of external funds.

We further observe that when $c_{1} q_{0}>c_{2} q_{\mathrm{A}}+A$, our findings are analogous and discussed in Online Appendix A (in the proof of Proposition 5). Moreover, because specific bounds on $c_{1}, y_{1}$, and $\beta$ are intractable, we numerically examine the impact of these constructs on the investment decision in Section 4, Online Appendix B, and Online Appendix D.

\subsection{Characterization of the Equilibrium Investment Amount}

In Section 3.2, we discussed the equilibrium friction and operational effects associated with investing in production cost reduction for a given investment amount $A$. We now characterize the equilibrium for $A$ when it is a continuous decision variable, such that the firm may choose to invest any amount $A \in[0, \bar{A}]$, where $\bar{A}$ denotes the technological limit on the investment amount-that is, the cutting-edge technology in the market that provides the highest cost reduction. Proposition 6 describes the equilibrium in the absence of capital market frictions.

Proposition 6. If $A$ is a continuous decision variable such that $A \in[0, \bar{A}]$ and $\bar{A} \leq c_{1} / \beta,{ }^{1}$ then in the absence of capital market frictions (i.e., $\gamma=0$ ) the firm's equilibrium investment decision is

$$
A^{*}=\left\{\begin{array}{lll}
\bar{A} & \text { if } & \bar{A}>A_{\text {th }} \\
0 & \text { if } & \bar{A}<A_{\text {th }}
\end{array} \text { where } A_{\text {th }}=\frac{2}{\beta}\left[\frac{p}{a \beta}-p+c_{1}\right]^{+} .\right.
$$

Consistent with the technology investment literature (Goyal and Netessine 2007), Proposition 6 shows that a threshold investment policy is optimal. The firm adopts the cutting-edge technology, $\bar{A}$, if the level of that technology is more advanced than the threshold $A_{t h}$. Although this result is known, examining the impact of capital market frictions on $A_{t h}$ is new. We thus investigate how the presence of capital market frictions conditions this investment threshold, where the lower the threshold, the more motivated the firm is to invest. We observe that firstand second-order derivatives of the firm's expected profit as a function of the investment decision in the presence of capital market frictions, are analytically intractable (as per Lemma A.1 in Online Appendix A). However, we can derive some analytical results as $A$ approaches its upper bound, as described in the next corollary.
Corollary 2. If $A$ is a continuous decision variable such that $A \in[0, \bar{A}]$ and $\bar{A} \leq c_{1} / \beta$, then in the presence of capital market frictions (i.e., $\gamma>0$ ),

$$
\begin{aligned}
& \lim _{A \rightarrow \bar{A}=\frac{c_{1}}{\beta}} \frac{\partial \pi_{A}}{\partial A}=a \beta-1>(<) 0 \text { if } \beta>(<) 1 / a \text { and } \\
& \lim _{A \rightarrow \bar{A}=\frac{c_{1}}{\beta}} \frac{\partial^{2} \pi_{A}}{\partial A^{2}}=\frac{(1-\gamma) a^{2} \beta^{2}+\gamma(2 a \beta-1)}{a p}>0 \text { if } \beta>1 / 2 a .
\end{aligned}
$$

Corollary 2 implies that as the investment amount approaches its upper limit (i.e., $A=\bar{A}=\frac{c_{1}}{\beta}$ ), the profit function becomes convex. Hence, if $\beta$ is not too small such that $\beta>\frac{1}{2 a}$ (to avoid investing to become infeasible even when there are no capital market fric-

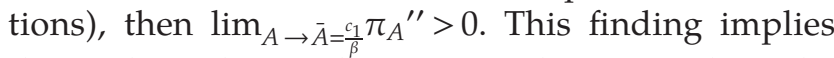
that a boundary solution may be optimal in the presence of capital market frictions (i.e., $\gamma>0$ ). In Section 4, we numerically verify that the profit function is still convex, and a threshold investment policy is optimal in the presence of capital market frictions. Hence, even when $A$ is a continuous decision variable, the search space for the optimal investment amount can be reduced to $A \in\{0, \bar{A}\}$, without loss of generality. This result implies that the analysis under continuous or fixed investment is identical because in either case the optimal decision derives from evaluating the investment amounts on the boundaries. In Section 4.3, we numerically illustrate the impact of capital market frictions on the investment threshold as a function of $c_{1}, y_{1}$, and $\beta$.

\section{Numerical Analysis}

We have demonstrated that the presence of capital market frictions can positively affect a firm's benefit from investing in production cost reductions. Thus, it is helpful to understand the conditions under which this positive effect takes place and how it changes when the capital-market-friction proportion $\gamma$ increases (we observe that the impact of $\gamma$ on the firm's expected profit is analytically intractable, as per Corollary C.1 in Online Appendix C). We first illustrate the parametric regions and conditions where investing in reducing a firm's unit production cost is optimal (i.e., $\Pi>0)$ both in the presence $(\gamma>0)$ and absence $(\gamma=0)$ of capital market frictions. We also illustrate how the presence of such frictions affects the firm's willingness to invest. We then examine when a firm achieves more benefit from the cost-reduction investment under capital market frictions, noting that this situation is equivalent to experiencing a positive friction effect (i.e., $\Delta R_{2}>0$ ), and consider how an increase in these frictions affects the net benefit from investing $(\partial \Pi / \partial \gamma)$ as well as the investment threshold $\left(A_{t h}\right)$. Moreover, because demand variations affect the supply-demand mismatch and the firm's exposure 
to capital market frictions, we relax Assumption 1 and consider a range of demand variance.

For expositional simplicity, we utilize the following nondimensional ratios in our numerical analyses. Initial capital is normalized with respect to the investment amount; that is, we work with $\frac{y_{1}}{A}$ and call it the initial capital ratio, a measure for the amount of risk-free capital available for funding production in the second stage. Similarly, the initial unit production cost is normalized with respect to price; that is, we work with $\frac{c_{1}}{p}$ and call it the initial cost ratio. A reduction in this ratio is used as a proxy for an increased profit margin (because the profit margin equals $1-\frac{c_{1}}{p}$ ). We set the ranges for these nondimensional ratios at $1 \leq \frac{y_{1}}{A} \leq 10$ and $0 \leq \frac{c_{1}}{p} \leq 10$ with $0 \leq \gamma \leq 1$, which address the entire set of relevant ratios and levels of capital market frictions. These ratios are constructed for varying levels of $y_{1}$ and $c_{1}$, while setting price $p$ to $\$ 10$ per unit and investment amount $A$ to $\$ 10$ (when the investment amount is continuous, $A$ can be thought of as $\bar{A}$, which is the upper bound of the investment domain, as explained in Section 3.3). The value choice for $p$ or $A$ has no impact, because the initial cost ratio $\left(\frac{c_{1}}{p}\right)$ and initial capital ratio $\left(\frac{y_{1}}{A}\right)$ drive the results.

We have run over 8,300 simulations, considering 19 values for $\frac{y_{1}}{A}$ with $\frac{y_{1}}{A} \in\{1,1.5,2, \ldots, 10\}, 21$ values for $\frac{c_{1}}{p}$ with $\frac{c_{1}}{p} \in\{0,0.05,0.1, \ldots 1\}$ and 21 values for $\gamma$ with $\gamma \in\{0,0.05,0.1, \ldots, 1\}$. Considering values beyond these ranges is either economically infeasible (e.g., $\gamma<0$ or $\gamma>1$, and $\frac{c_{1}}{p}<0$ or $\frac{c_{1}}{p}>1$ ) or likely to result in a financially unconstrained problem (e.g., $\frac{y_{1}}{A}>10$ ). For our base case analysis, the value of the unit production cost reduction $\beta$ per dollar invested is set at 0.15 and demand variability parameter $\Delta$ at 10 (i.e., the demand follows a uniform probability distribution with support $\left.\left[\frac{a}{2}-\Delta, \frac{a}{2}+\Delta\right]\right)$. We then test the robustness of our results for $\beta=\{0.05,0.1,0.15,0.20,0.25\}$ and $\Delta=\{0,2,4,6,8,10\}$. Parameter values beyond these ranges do not generate any new insights. Changing the nature of the demand distribution from uniform to normal does not materially affect our results either. Consequently, we focus on a uniform demand distribution with $a=20$ (we discuss the normally distributed demand scenario in Online Appendix B.3).

\subsection{Equilibrium Investment Decision and Friction Effect}

Figure 4 portrays the range of parameters where it is optimal to invest in production cost reduction, and where the friction effect is positive or negative. The investment space is divided into four regions. Region I depicts the value range for the initial cost ratio and initial capital ratio where investment is not meaningful because the unit production $\operatorname{cost} c_{2}$ becomes negative. Region II depicts the value range where the firm has sufficient funds to operate smoothly. Region III depicts the value range where the firm is financially constrained, and it is optimal to invest in production cost reductions (i.e., $\Pi>0$ ). Region III is subdivided into three regions based on the sign of the friction effect derived from Proposition 3. Region IV-A depicts where it is suboptimal to invest even in a perfect capital market (i.e., when $\gamma=0$ ). Region IV-B depicts the impact of capital market friction on the firm's willingness to invest. In particular, it shows the reduction in parameter combinations under which the firm invests after increasing the level of $\gamma$ from 0 to 1 -that is, the dashed line moves clockwise-because introducing capital market frictions discourages the firms from investing in that region where the initial cost ratio is high, but the initial capital ratio is low.

If we examine the investment regions in more detail, we first observe that subregion III-A represents a firm with a tight capital constraint (small $\left.\frac{y_{1}}{A}\right)$, but with high potential to benefit from investing (low $\left.\frac{c_{1}}{p}\right)$. With no capital market frictions, the firm benefits more from investing when the unit production cost is low (recall that, when $\gamma=0$, benefit from investing reduces to $\Delta R_{1}$, which decreases with $c_{1}$ ). In this subregion, the firm also faces high costs for external funds-a steep $\operatorname{MCE}(q \mid$ no investment $)$ curve-due to its small initial capital. However, because the unit production cost is low, investing to further reduce the production cost can significantly increase the firm's future cash flow and thus reduce its financial risk and its external funding costs. As a result, we observe a positive friction effect $\Delta R_{2}$. Similarly, subregion III-C represents a firm with a loose capital constraint (large $\frac{y_{1}}{A}$ ) and a low potential to benefit from investing (high $\frac{c_{1}}{p}$ ). The firm thus faces a relatively low cost for external funds, represented by a rather flat $\operatorname{MCE}(q \mid$ no investment $)$ curve. Investing thus increases the firm's future cash flow, but compared with the decrease in risk-free cash reserves, the overall financial risk and costs of external funds increase, creating a negative friction effect $\Delta R_{2}$. In subregion III-B, $\Delta R_{2}$ could be positive or negative depending on the value of the capital-market-friction proportion $\gamma$.

As discussed in Proposition 3, the unit production cost reduction $\beta$ per dollar invested is a key driver of the positive friction effect. To test the robustness of our results, we have reproduced Figure 4 for five different values for $\beta$. For brevity, we present these figures in Online Appendix B.2 and focus herein on the main takeaways. When $\beta$ is too low (e.g., $\beta=0.05$ ), the investment region (region III) is empty. As $\beta$ increases, the investment region expands, which motivates the firm to invest for a wider range of parameter combinations. Firms with high values for $\beta$ are more likely to face a positive friction effect (i.e., region III-A 
Figure 4. (Color online) Joint Characterization of the Firm's Investment Decision and the Friction Effect $\Delta R_{2}$

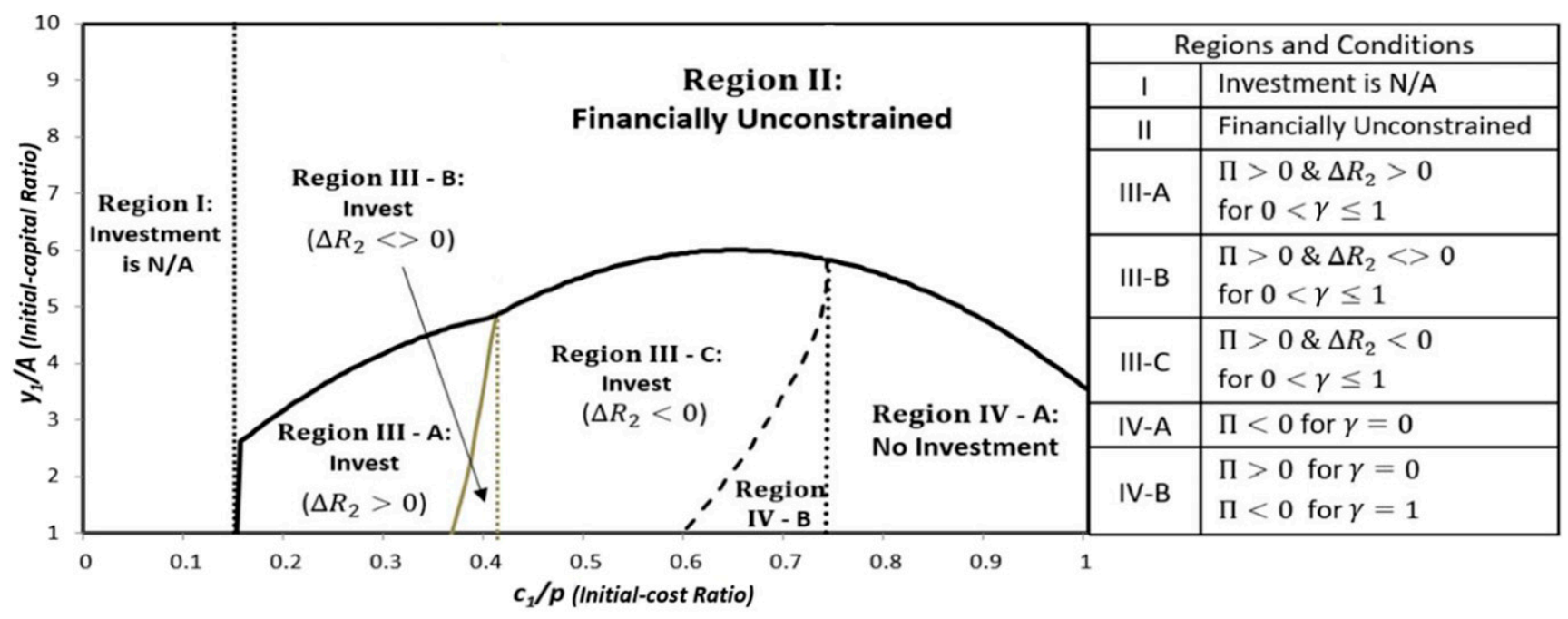

expands with $\beta$ ) and from Proposition 3, a threshold value $\hat{\beta}$ exists above which the firm invests and faces a positive friction effect. We also introduce a threshold $\beta$ above which the firm will choose to invest. Figure 5(a) illustrates these thresholds for a fixed capital-market-friction proportion $\gamma$ and varying levels of $\frac{y_{1}}{A}$, and Figure 5(b) illustrates them for a fixed $\frac{y_{1}}{A}$ and varying levels of $\gamma$.

For the parameter combinations in Figure 5, a higher initial cost ratio reduces the benefit from investing and increases both thresholds $\hat{\beta}$ and $\beta$. For a given initial cost ratio, lower levels of initial capital ratio or higher levels of capital market frictions has two effects: (1) deter the firm from investing (i.e., $\beta$ increases) and (2) increase the threshold for facing a positive friction effect (i.e., $\hat{\beta}$ increases). Intuitively, the lower ratio and high frictions augment the firm's ex ante cost for external funds, which creates more room for reducing this cost through investing in cost reduction. However, to exploit this possibility of creating a positive friction effect, the firm requires a higher investment efficiency or, equivalently, a higher unit production cost reduction $\beta$.

We also observe in Figure 4 that the delineation of regions and subregions that characterize when it is optimal to invest in production cost reduction (along with the sign of the friction effect) enables us to further scrutinize how the net benefit from investing changes as capital market frictions increase (i.e., $\partial \Pi / \partial \gamma)$. We recall that only the friction effect $\Delta R_{2}$ depends on capital market frictions (i.e., the operational effect is constant with respect to $\gamma$ ); thus, analyzing $\partial \Pi / \partial \gamma$ is equivalent to analyzing $\partial \Delta R_{2} / \partial \gamma$. Figure 6 illustrates when $\Delta R_{2}$ (or $\Pi$ ) increases or decreases with changes in capital market frictions. A comparison of Figures 4 and 6 offers additional

Figure 5. Impact of $\frac{c_{1}}{p}$ and $\frac{y_{1}}{A}$ and $\gamma$ on $\hat{\beta}$ and $\underline{\beta}$

(a)

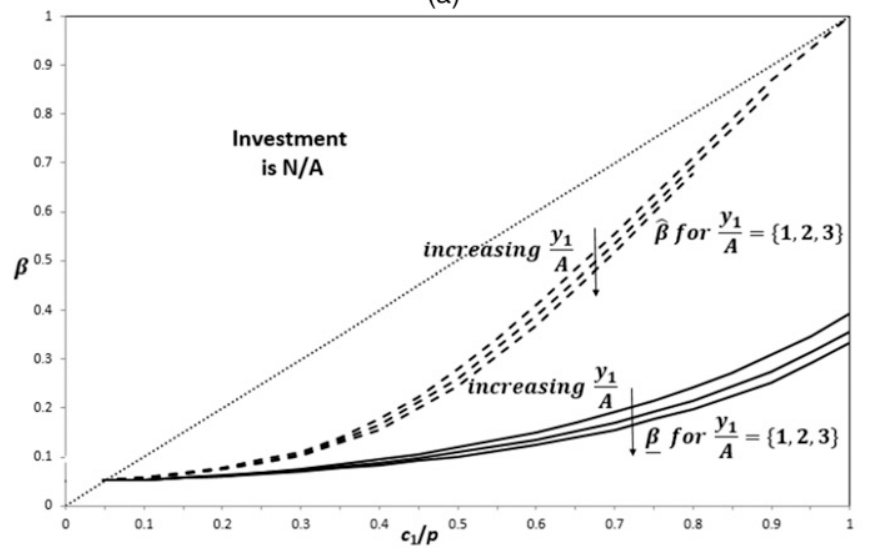

(b)

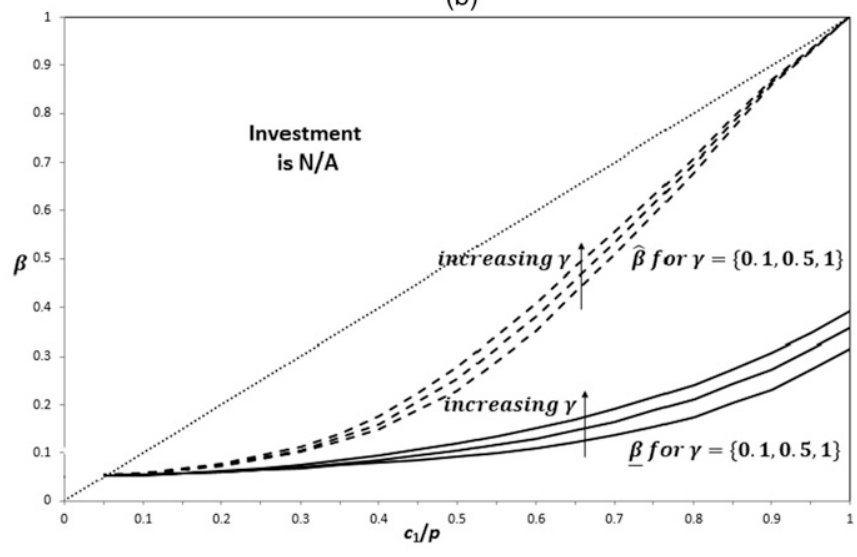

Notes. In panel (a), $\gamma=1$ and $y_{1} / A \in\{1,2,3\}$. In panel (b), $\gamma \in\{0.1,0.5,1\}$ and $y_{1} / A=1$. 
Figure 6. (Color online) Joint Characterization of the Firm's Investment Decision and the Marginal Impact $\partial \Pi / \partial \gamma$ of Capital Market Frictions on the Investing Net Benefit

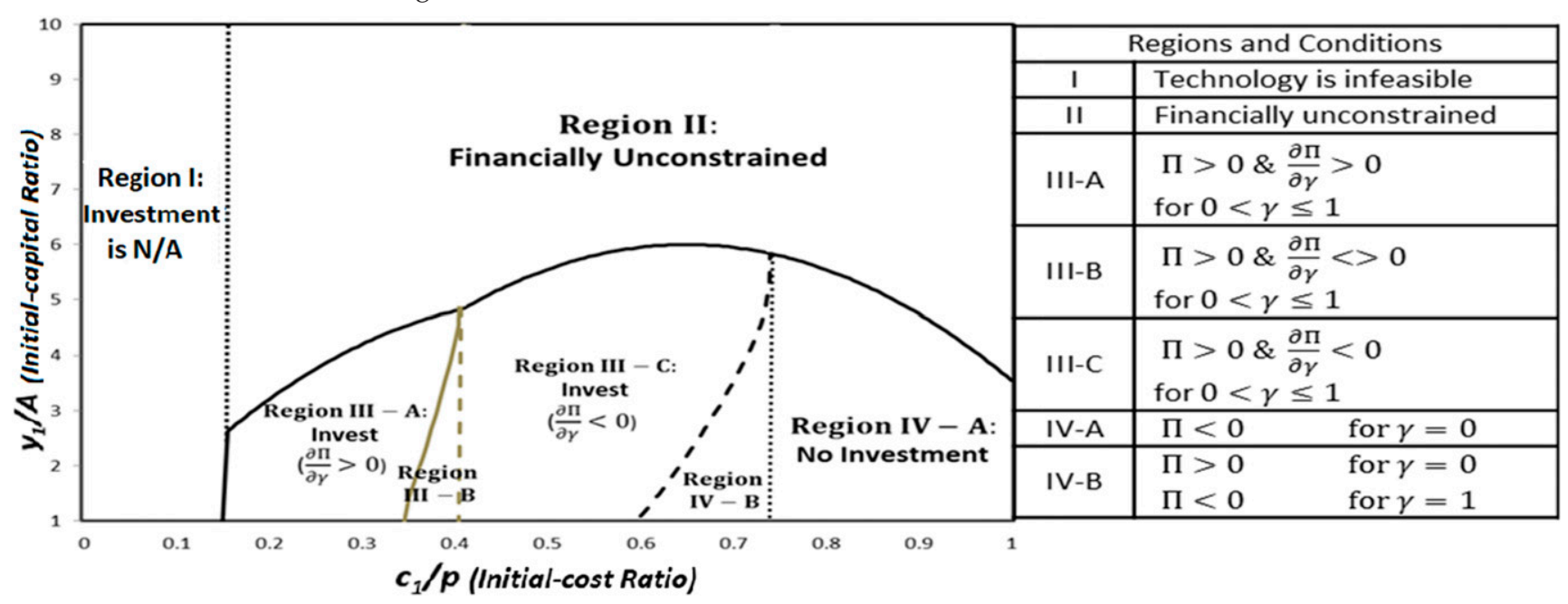

insights. When the friction effect is negative (i.e., $\Delta R_{2}<0$ ), the net benefit from investing always decreases with the capital-market-friction proportion $\gamma$ (i.e., $\partial \Pi / \partial \gamma<0$ ). However, when the friction effect is positive, tightening the access to external funds (via an increase in $\gamma$ ) can increase this net benefit. Therefore, the impact of capital market frictions on a firm's net benefit from investing in production cost reduction depends on the sign of the friction effect, and further tightening a firm's access to external funds does not necessarily decrease this net benefit.

\subsection{Impact of Demand Uncertainty}

We also numerically explore the impact of demand uncertainty on our results. We assume that demand $\xi$ follows a uniform probability distribution with support $\left[\frac{a}{2}-\Delta, \frac{a}{2}+\Delta\right]$. In particular, we set $a$ at 20 units (as in Section 4.1) and consider six levels of demand variability with $\Delta \in\{0,2,4,6,8,10\}$, while keeping all other parameters identical to those in Figure 4. This analysis enables us to examine a special condition for the demand distribution, where not only the variance is reduced but also the support is restricted to a nonzero lower bound, and, consequently, a portion of the demand is guaranteed.

Figure 7 illustrates a pattern of results consistent with Figure 4 (where demand uncertainty is maximal and thus $\Delta=10)$. The approach used to set up regions I, II, III, and IV is identical to that in Figure 4. In addition, a new subregion III-D emerges (for lower levels of variability), where a firm uses external funds, and yet the friction effect $\Delta R_{2}=0$, because the firm's cash flows are guaranteed to cover the loan repayment. We label this a risk-free borrowing region, consistent with the nomenclature suggested by Boyabatli and Toktay (2011). This region's creation results from the fact that when $0<\Delta<\frac{a}{2}$, a certain amount of demand $\left(\frac{a}{2}-\Delta\right)$ is guaranteed, which enables the firm to borrow at a risk-free rate. A comparison of Figure 7, (a), (b), and (c) makes two additional observations. First, more demand uncertainty (i.e., increasing levels of $\Delta$ ) discourages investing in production cost reduction, because it increases the negative impact of capital market frictions on the firm's profit. Indeed, an increase in demand uncertainty expands the region in which investing is suboptimal (region IV grows with $\Delta$ ). Second, we observe that demand should be sufficiently variable to experience a positive friction effect. For instance, subregion III-A is empty when $\Delta=6$ in Figure 7(c). Demand uncertainty increases the financial risk and creates more opportunities for investment to reduce the cost of using external funds. We omitted $\Delta \in\{0,2,4\}$ in Figure 7 because, under low-demand variability, risk-free borrowing characterizes the entire investment region (region III) as the firm's guaranteed revenues fully collateralize the borrowing needs under all parameter combinations.

\subsection{Impact of Capital Market Frictions on the Investment Threshold}

We conclude this section by examining the impact of capital market frictions on the investment amount threshold $A_{t h}$. Although the derivatives of the firm profits are intractable in the presence of capital market frictions (as per Lemma A.1 in Online Appendix A), we have verified that for all relevant parameter ranges (as described in Section 4), the threshold policy remains optimal. Figure 8 illustrates the impact of capital market frictions on the investment threshold as a function of initial capital $y_{1}$ and initial unit $\operatorname{cost} c_{1}$. We observe in Figure 8(a) that firms with high initial unit 
Figure 7. (Color online) Characterization of the Firm's Investment Decision and the Friction Effect $\Delta R_{2}$ for $\Delta \in\{6,8,10\}$

(a)

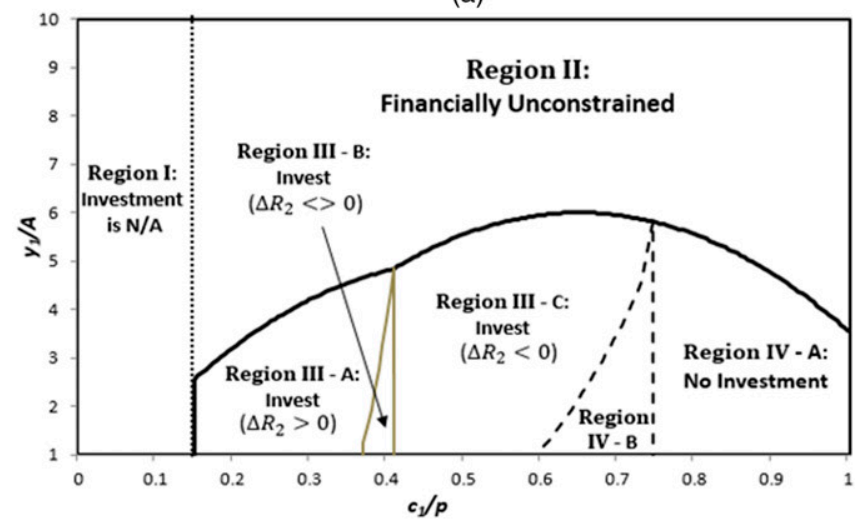

(c)

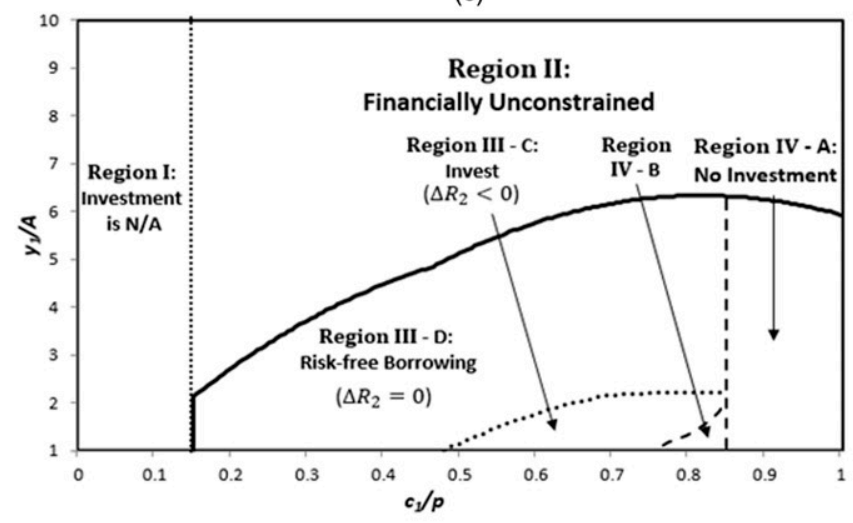

(b)

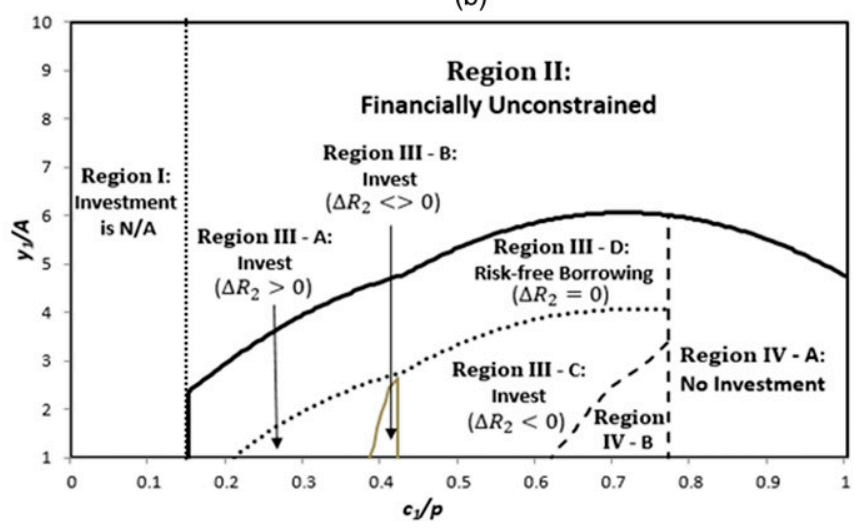

(d)

\begin{tabular}{|c|l|}
\hline \multicolumn{2}{|c|}{ Regions and Conditions } \\
\hline I & Investment is N/A \\
\hline II & Financially Unconstrained \\
\hline III-A & $\begin{array}{l}\Pi>0 \& \Delta R_{2}>0 \\
\text { for } 0<\gamma \leq 1\end{array}$ \\
\hline III-B & $\begin{array}{l}\Pi>0 \& \Delta R_{2}<>0 \\
\text { for } 0<\gamma \leq 1\end{array}$ \\
\hline III-C & $\begin{array}{l}\Pi>0 \& \Delta R_{2}<0 \\
\text { for } 0<\gamma \leq 1\end{array}$ \\
\hline III-D & $\begin{array}{l}\Pi>0 \& \Delta R_{2}=0 \\
\text { for } 0<\gamma \leq 1\end{array}$ \\
\hline IV-A & $\Pi<0$ for $\gamma=0$ \\
\hline IV-B & $\begin{array}{l}\Pi>0 \text { for } \gamma=0 \\
\Pi<0 \text { for } \gamma=1\end{array}$ \\
\hline
\end{tabular}

Notes. In panel (a), $\Delta=10$. In panel (b), $\Delta=8$. In panel (c), $\Delta=6$. Panel (d) is the legend.

cost benefit less from investing, and hence require a higher cutting-edge technology level $A_{t h}$ to invest. Increasing capital market frictions also makes external funds more expensive and further reduces the benefit from investing, which leads to even higher investment thresholds. For instance, when $c_{1}=6.5$, in a perfect capital market the firm can adopt any technology in the market $\left(A_{t h}=0\right)$, but for $\gamma=0.5$ or $\gamma=1$, the firm will invest only if the cutting-edge technology level equals or exceeds $A_{t h}=8.3$ or 18.2 , respectively.

Figure 8. Equilibrium Investment Thresholds $A_{t h}$ as a Function of $c_{1}, y_{1}$, and $\gamma$

(a)

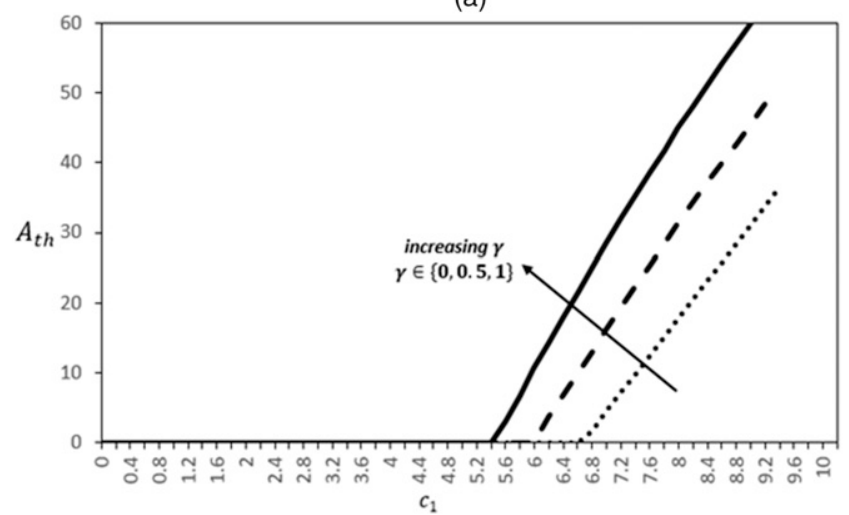

(b)

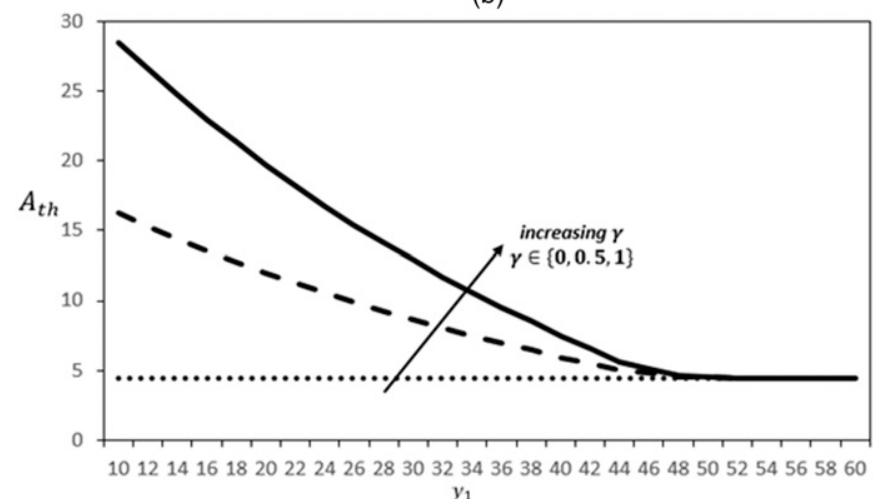

$y_{1}$

Notes. In panel (a), $y_{1}=10$ and $c_{1} \in[0,10]$. In panel (b), $c_{1}=3$ and $y_{1} \in[10,60]$. 
Moreover, when initial capital $\left(y_{1}\right)$ is sufficiently large, Figure 8(b) suggests that the presence of capital market frictions does not affect the investment amount threshold $A_{t h}$, because the firm does not need to borrow. Consequently, $A_{t h}$ for $\gamma \in\{0,0.5,1\}$ converges to the perfect market level (i.e., $A_{t h}=$ $\frac{2}{\beta}\left[\frac{p}{a \beta}-p+c_{1}\right]^{+}$, as described in Proposition 6). We also observe that as the firm becomes more financially constrained (i.e., as $y_{1}$ decreases), $A_{t h}$ remains constant under a perfect market (i.e., when $\gamma=0$ ), but it increases when $\gamma>0$. In particular, as the initial capital diminishes, the financial risk exponentially increases, which results in higher investment amount thresholds.

\section{Extension: Uncertainty About the Unit Production Cost Reduction}

We extend our results by adding uncertainty in the firm's unit production cost reduction $\beta$ per dollar invested, which enables us to characterize when a firm can benefit from such uncertainty in the presence of capital market frictions. This uncertainty can originate from various sources, including an underlying production-cost-reduction technology's implementation (e.g., how well standard equipment fits the firm's need) or readiness (e.g., it was only pilot tested instead of implemented in an industrial-scale chemical plant). Evidence from our illustrative examples of BigFoot Networks and Faradox also suggests that a firm might have to anticipate such reduction with a probability distribution. We then discuss the joint characterization of the firm's investment decision and friction effect by making a comparison with our findings in Section 4.

We consider a normally distributed unit production cost reduction per dollar invested with mean $\bar{\beta}$, standard deviation $\sigma$, and coefficient of variation $C V_{\beta}=\sigma / \bar{\beta}$. We assume that the firm observes the actual realization of $\beta$ after the investment decision, but prior to the production commitment, and we accordingly revise the time line of events in our baseline model. Specifically, the firm invests at $t=1$, observes the realization of $\beta$ at $t=2$, and then selects the equilibrium production quantity, $q_{A}(\beta)$, by solving

$$
\begin{aligned}
\pi_{A}(\beta)= & \max _{q(\beta)}\left\{E_{\xi}[p \min (q(\beta), \xi)]-c_{2} q(\beta)\right. \\
& -E_{\xi}\left[\gamma p \min (q(\beta), \xi) I_{\{p \min (q(\beta), \xi) \leq F(q(\beta))\}]\}}-A,\right.
\end{aligned}
$$

where $F(q(\beta))$ is given by,

$$
\begin{aligned}
E_{\xi} & \{\max [p \min (q(\beta), \xi), F(q(\beta))]\} \\
& -E_{\xi}\left\{\gamma p \min (q(\beta), \xi) I_{\{p \min (q(\beta), \xi) \leq F(q(\beta))\}\}}\right\} \\
& =c_{2} q(\beta)-y_{2} .
\end{aligned}
$$

Expected profit with or without investment at $t=1$ is, respectively, $\pi_{A}=E_{\beta}\left[\pi_{A}(\beta)\right]$ or $\pi_{0}=E_{\beta}\left[\pi_{0}(\beta)\right]$.

For our analysis herein, we focus on varying the coefficient of variation $C V_{\beta}$, which we refer to as production-cost-reduction uncertainty. For a perfect capital market, adding this uncertainty increases the firm's benefit from investing (because in the absence of frictions, the investment benefits reduces to $\Delta R_{1}$, which is a convex function of the firm's unit production cost reduction $\beta$ per dollar invested). However, in the presence of capital market frictions, adding this uncertainty affects the cost of external funds and, consequently, the impact on the firm's investment benefits is not straightforward. Compared with Figure 4, we first observe in Figure 9 that adding uncertainty to the production cost reduction shrinks the parameter space where the firm is financially unconstrained; that is, region II shrinks. As this uncertainty affects the realizations of the unit production cost, it also introduces uncertainty to the production quantity and to the amount of external funds needed, which, in turn, forces the firm to depend on external funds more often. Second, adding uncertainty to the production cost reduction expands the optimal investment space; that is, region III expands. The impact of adding this uncertainty increases variability in the firm's cash flow, which increases its financial risk, but it also increases the firm's expected cash flow (because benefit from investing is a convex function of $\beta$ when there is no friction) and results in motivating the firm to optimally invest under a larger set of combinations of initial cost ratio and initial capital ratio.

We also offer a third insight that is more complex and insightful than the above two: adding uncertainty to the production cost reduction shrinks (expands) the region for a positive (negative) friction effect; that is, region III-A shrinks, but region III-C expands. We first examine a particular point in region III-A of Figure 9 (e.g., $\frac{c_{1}}{p}=0.3$ and $\frac{y_{1}}{A}=1$ ); that is, a set of parameters where the friction effect $\Delta R_{2}$ is positive. In Figure $10(\mathrm{a})$, we plot the friction effect $\left(\Delta R_{2}\right)$, operational effect $\left(\Delta R_{1}\right)$, and benefit from investing $(\Pi=$ $\left.\Delta R_{1}+\Delta R_{2}-A\right)$ at this particular point for varying levels of the capital market frictions and production-costreduction uncertainty. Consistent with Figure 6, we observe that the friction effect $\Delta R_{2}$ increases when the level of frictions increases. However, this positive friction effect decreases when the production-costreduction uncertainty increases, which explains the shrinking of region III-A, owing to a reduction in the cost of external funds, which, in turn, reduces the potential to save on such costs when investing. As for the operational effect $\Delta R_{1}$, it increases when the production-cost-reduction uncertainty increases as discussed before. But the net benefit $\Pi$ from investing 
Figure 9. (Color online) Joint Characterization of the Firm's Investment Decision and the Friction Effect $\Delta R_{2}\left(C V_{\beta}=0.33\right)$

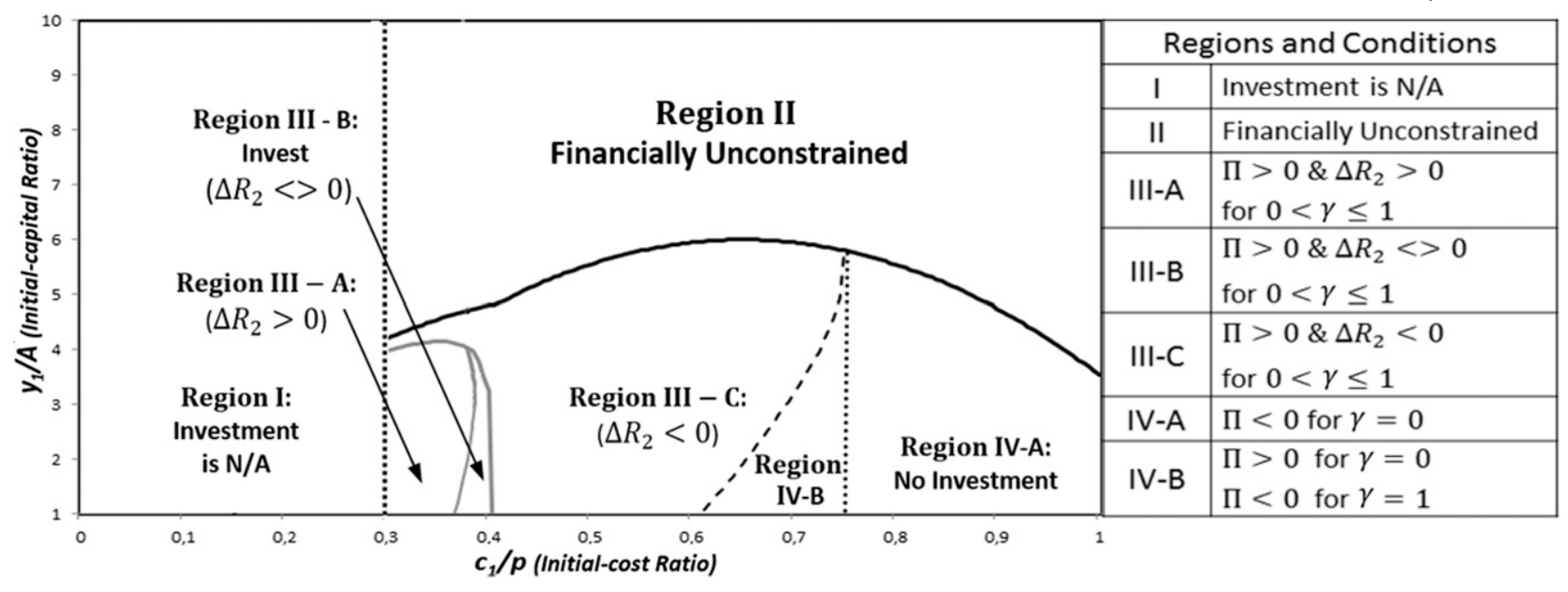

then increases when the production-cost-reduction uncertainty increases because of the increase in $\Delta R_{1}$ dominating the reduction in $\Delta R_{2}$.

Next, we examine a particular point in Region III-C of Figure 9 (e.g. $\frac{c_{1}}{p}=0.45$ and $\frac{y_{1}}{A}=1$ ), where the friction effect $\Delta R_{2}$ is negative. In this case, Figure $10(\mathrm{~b})$ shows that $\Delta R_{2}$ now increases (i.e., becomes less negative) when the production-cost-reduction uncertainty increases. In other words, the volatile production cost reduction mitigates the negative friction effect. And because $\Delta R_{1}$ also increases when that uncertainty increases, so does the net benefit $\Pi$ from investing.

Figure 10. Impact of $\gamma$ and $C V_{\beta}$ on $\Delta R_{2}, \Delta R_{1}$ and $\Pi$
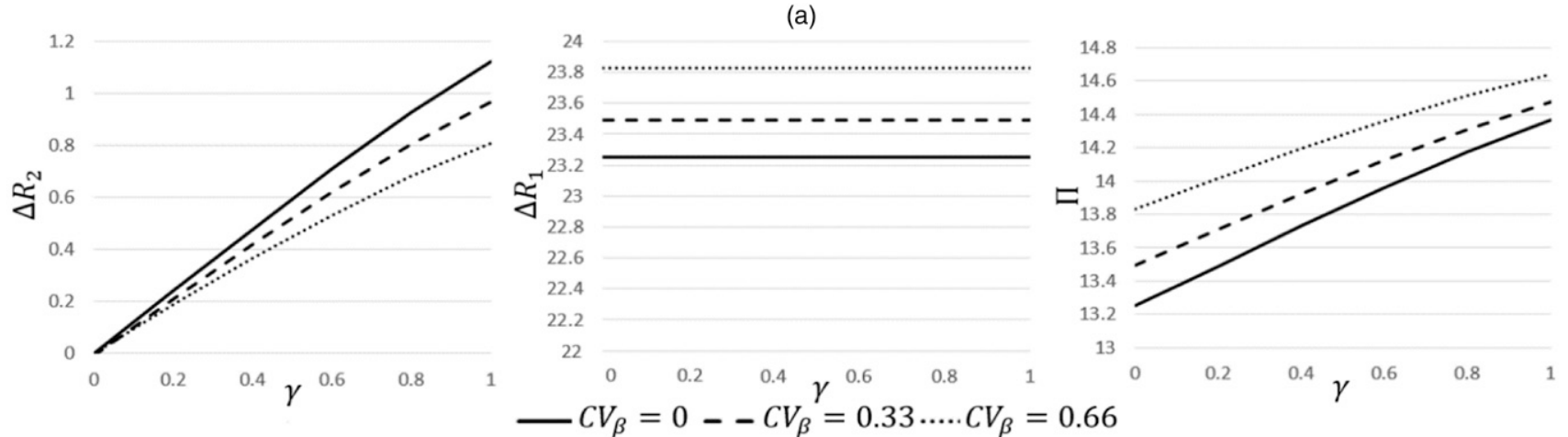

(b)
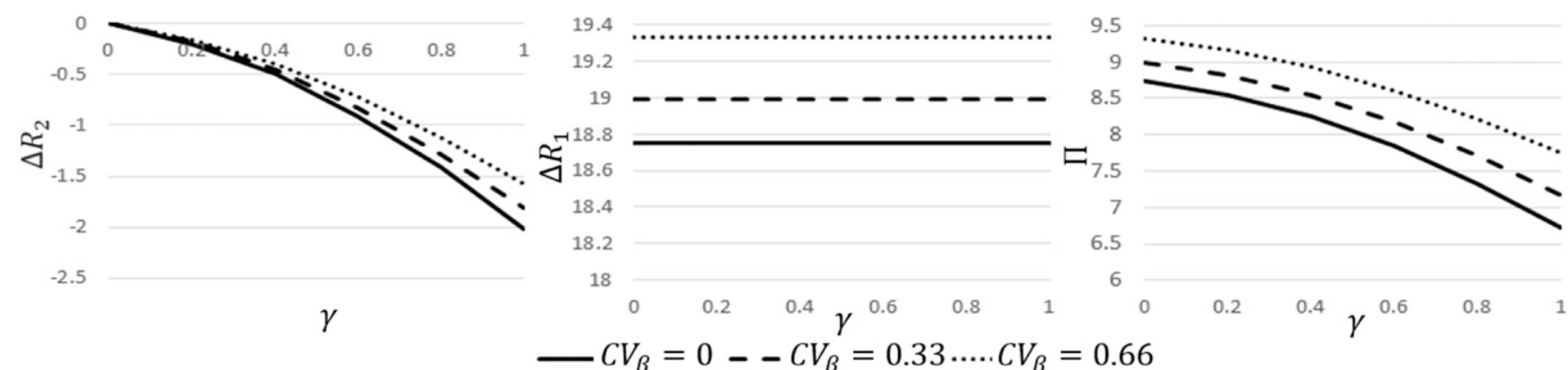

Notes. In panel (a), $\Delta R_{2}(>0), \Delta R_{1}$, and $\Pi$ are functions of $\gamma$ and $C V_{\beta}$ for $\frac{c_{1}}{p}=0.3$ and $\frac{y_{1}}{A}=1$. In panel (b), $\Delta R_{2}(<0), \Delta R_{1}$, and $\Pi$ are functions of $\gamma$ and $C V_{\beta}$ for $\frac{c_{1}}{p}=0.45$ and $\frac{y_{1}}{A}=1$. 
Overall, we observe that the net benefit from investing increases in the production-cost-reduction uncertainty both in perfect $(\gamma=0)$ and imperfect capital markets $(\gamma>0)$, but to a lesser (larger) extent in the latter one when $\Delta R_{2}>0$ (respectively, $\Delta R_{2}<0$ ). Therefore, uncertainty reduces the positive friction effect while increasing the negative friction effect. We believe that this is a unique result, as it ties the impact of productioncost-reduction uncertainty and capital market frictions on the benefit from investing. Online Appendix B.4 offers a discussion on the robustness of the behaviors exhibited in Figure 10 by examining the sign of the partial derivative of the friction effect with respect to the standard deviation in the production cost reduction (i.e., $\partial \Delta R_{2} / \partial \sigma$ ).

\section{Conclusion}

This research extends an emerging body of work by first investigating the conditions under which a firm would benefit by investing in unit production cost reduction measures in the presence of capital market frictions. We characterized how the level of capital market frictions could affect the net benefit (i.e., additional profit) from investing in production cost reduction efforts. Moreover, we analyzed how demand uncertainty might affect the productioncost-reduction investment decision in the presence of capital market frictions, and how uncertainty in the unit production cost reduction per dollar invested might condition the impact of those frictions. We put forward four major insights (I1 through I4) that summarize our analysis of this investment decision, and the conditions that favor investing in anticipation of the production decision. We then discuss the consequences of these insights.

I1. A firm can achieve greater net benefits by investing in production cost reduction in the presence of capital market frictions than in their absence.

I2. When considering a firm with small initial capital relative to the capital amount invested to reduce its unit production cost (i.e., a low initial capital ratio), but with a product that exhibits a low preinvestment production cost relative to its price (i.e., low initial cost ratio), we find that it can achieve greater benefits by investing in production cost reduction when capital market frictions are high than when they are low. In addition, depending on the sign of the friction effect, the firm's initial capital may either increase or decrease the benefit from investing.

I3. When considering a firm for which the reduction in the unit production cost per dollar invested is uncertain, we find that if it faces a reduction in external fund costs after investing in production cost reduction-a financial benefit-then introducing more uncertainty in the production cost reduction decreases this benefit; but if the firm faces a growth in external fund costs after investing in production cost reduction-a financial loss-then increasing this uncertainty decreases this loss.

I4. An increase in demand uncertainty reduces the size of the region where the pairings of a firm's initial cost ratio and initial capital ratio render investing optimal.

From a theory perspective, our four insights (I1 to I4) expand upon the very few recent studies on operational flexibility in the presence of capital market frictions highlighted in the bottom-right quadrant of Table 1 (i.e., Boyabatli and Toktay 2011, Iancu et al. 2016). Insights I1 and I2 establish conditions for a positive impact of capital market frictions on a firm's net benefit from investing in production cost reduction based on the trade-off between two crucial effects. First, investing reduces the unit production cost, thus expanding the firm's production capabilities / quantities and increasing its expected profit at the end of the production stage, which eases access to external funds. Second, investing consumes the firm's risk-free capital, which can restrict access to external funds. If the former effect dominates the latter, then the firm faces lower costs of external funds, which we have called a positive friction effect. Firms are therefore encouraged to consider this effect and, most importantly, the underlying trade-off as key factors when selecting between production-cost-reduction approaches to create operational hedges.

The underlying trade-off that shapes the sign of the friction effect also plays a role when considering the impact of a firm's initial capital on the benefit from investing in production cost reduction (Online Appendix D offers technical details). When a firm possesses more initial capital, it is intuitive to assume that it would reap greater benefits from investing in reducing unit production costs than when it possesses less initial capital, because its exposure to capital market frictions decreases and, consequently, the cost of external funds decreases. However, we found that this assumption holds only when the friction effect is negative; that is, when investing increases the cost of external funds. When the friction effect is positive, a firm with more initial capital benefits less from investing than a firm with less initial capital, because by lowering the friction effect, more initial capital can substitute the aim of the investment: to mitigate the firm's exposure to capital market frictions.

This positive friction effect also complements the findings of Iancu et al. (2016) on the impact of operational flexibility in the presence of agency problems. While we focus on production cost reduction rather than operational flexibility, our analysis reveals that investing in production cost reduction can create a hedge against a firm's exposure to capital market frictions. We demonstrate that a firm can reap 
greater benefits from investing in production cost reduction measures when capital market frictions are high, owing to a positive friction effect. We therefore find that under the right circumstances and in the presence of capital market frictions, a positive friction effect can create additional benefits for a broad class of operational hedges. Under other circumstances, we observe that uncertainty in production cost reduction mitigates the impact of capital market frictions on a firm's net benefit from investing in such reduction, as highlighted in insight I3. Moreover, insight I4 complements Boyabatli and Toktay's (2011) work, which also investigates the impact of a firm's demand uncertainty on its investment decisions, because it implies that by increasing demand uncertainty, the investment in reducing unit production cost becomes less attractive in the presence of capital market frictions.

When deciding whether to invest in production cost reduction, a firm can employ quantifiable input parameters, such as initial cost ratio and initial capital ratio, to assess the net benefit from investing in the presence of capital market frictions. Based on our fieldwork at firms such as Faradox and BigFoot Networks, managers do, in fact, estimate these parameters (and others that we have used to build our theoretical decision model) before they make production-cost-reduction investments. Our analysis and especially our insights I1 to I3 can provide some guidance on these investment decisions by offering a preliminary agenda from empirically testable hypotheses. This investigation also offers public policy implications for promoting production cost reduction in specific sectors. For instance, production size is typically linked to number of employees and thus public policies aimed at small or nascent firms facing high levels of capital market frictions, such as in loan guarantees, often seek production-cost-reduction outcomes that help to increase employment (Moniz 2014). Tracking the gains in production quantities and employment figures associated with production-costreduction investment through loan guarantees raises important empirical questions that can be answered by our findings, particularly the finding emphasized in I2 (for data-tracking examples, see DOE 2015). Exploring whether these loans were made to firms with a low initial cost ratio and small initial capital ratio, rendering the production-cost-reduction investment the best option, could be a fruitful empirical investigation.

As with all research, ours presents limitations. We focus on scenarios in which all external funds come from debt and use a fixed price for the firm's offering, and we model a linear reduction in the unit production cost, to name a few limitations. We could, for instance, alter this linear reduction so as to exhibit decreasing marginal return with respect to $\beta$ (e.g., from $c_{2}=c_{1}-\beta A$ to $c_{2}=c_{1}-\sqrt{\beta} A$ ). In this case, we have numerically verified that a firm which does not benefit from a higher level of uncertainty in the production cost reduction in the absence of frictions, may benefit from such uncertainty in the presence of frictions (for details, see Online Appendix E). Although more work is required to fully disentangle the trade-offs that underlie these findings, we believe this work provides a useful point of departure for studying alternative production-cost-reduction investment options (e.g., flexible technologies) and financing decisions in the presence of capital market frictions.

\section{Endnote}

${ }^{1}$ We note that $c_{1} / \beta$ is the largest value of $A$ such that the unit production cost remains nonnegative.

\section{References}

Alan Y, Gaur V (2018) Operational investment and capital structure under asset-based lending. Manufacturing Service Oper. Management 20(4):637-654.

Babich V (2010) Independence of capacity ordering and financial subsidies to risky suppliers. Manufacturing Service Oper. Management 12(4):583-607.

Balcer Y, Lippman SA (1984) Technological expectations and adoption of improved technology. J. Econom. Theory 34(2):292-318.

Blum JM (2002) Subordinated debt, market discipline, and banks' risk taking. J. Banking Finance 26(7):1427-1441.

Boyabatli O, Toktay LB (2004) Operational hedging: a review with discussion. Working paper, Lee Kong Chian School of Business, Singapore Management University, Singapore.

Boyabatli O, Toktay LB (2011) Stochastic capacity investment and flexible vs. dedicated technology choice in imperfect capital markets. Management Sci. 57(12):2163-2179.

Brander A, Lewis R (1988) Bankruptcy costs and the theory of oligopoly. Canadian J. Econom. 21(2):221-243.

Brealey R, Myers S, Allen F (2016) Principles of Corporate Finance, 12th ed. (McGraw-Hill, New York).

Brooks R (2017) Scaling high-performance computing to manufacturers' needs. Amer. Machinist (February 8), http://www .americanmachinist.com/enterprise-software/scaling-high -performance-computing-manufacturers-needs.

Carrillo JE, Gaimon C (2004) Managing knowledge-based resource capabilities under uncertainty. Management Sci. 50(11):1504-1518.

Chod J, Rudi N, Van Mieghem JA (2010) Operational flexibility and financial hedging: Complements or substitutes? Management Sci. 56(6):1030-1045.

Dada M, Hu Q (2008) Financing newsvendor inventory. Oper. Res. Lett. 36(5):569-573.

DOE (2015) Energy.gov. Accessed February 5, 2018, http://energy.gov/ maps/loan-program-office.

Dong L, Kouvelis P, Wu X (2014) The value of operational flexibility in the presence of input and output price uncertainties with oil refining applications. Management Sci. 60(12): 2908-2926.

Froot K, Scharfstein D, Stein J (1993) Risk management: coordinating corporate investment and financing policies. J. Finance 48(5): 1629-1658.

Gordon L (2005) Technologies to reduce production costs. Amer. Machinist (September 11), https://www.americanmachinist .com/features/technologies-reduce-production-costs. 
Goyal M, Netessine S (2007) Strategic technology choice and capacity investment under demand uncertainty. Management Sci. 53(2): 192-207.

Gupta S, Loulou R (1998) Process innovation, product differentiation, and channel structure: strategic incentives in a duopoly. Marketing Sci. 17(4):301-316.

Huchzermeier A, Cohen MA (1996) Valuing operational flexibility under exchange rate risk. Oper. Res. 44(1):100-113.

Iancu D, Trichakis N, Tsoukalas G (2016) Is operating flexibility harmful under debt? Management Sci. 63(6):1730-1761.

IDC (2018) Worldwide spending on digital transformation will soar past $\$ 1$ trillion in 2018, led by the manufacturing industries, according to a new IDC spending guide. Report, International Data Corporation, Framingham, MA.

Kouvelis P, Tian Z (2014) Flexible capacity investments and product mix: Optimal decisions and value of postponement options. Production Oper. Management 23(5):861-876.

Kouvelis P, Zhao W (2011) The newsvendor problem and price-only contract when bankruptcy costs exist. Production Oper. Management 20(6):921-936.

Kouvelis P, Zhao W (2015) Supply chain contract design under financial constraints and bankruptcy costs. Management Sci. 62(8): 2341-2357.

Lai G, Debo LG, Sycara K (2009) Sharing inventory risk in supply chain: the implication of financial constraint. Omega 37(4): 811-825.

Leland HE (1994) Corporate debt value, bond covenants, and optimal capital structure. J. Finance 49(4):1213-1252.

Leland HE, Toft KB (1996) Optimal capital structure, endogenous bankruptcy, and the term structure of credit spreads. J. Finance 51(3):987-1019.

Li G, Rajagopalan S (2008) Process improvement investments and learning: a real options approach. Production Oper. Management 17(1):61-74.

Luo W, Shang K (2014) Managing inventory for entrepreneurial firms with trade credit and payment defaults. Working paper, Duke University, Durham, NC.
Marschak T, Shanthikumar G, Zhou J (2015) A newsvendor who chooses informational effort. Production Oper. Management 24(1): 110-133.

Modigliani F, Miller M (1958) The cost of capital, corporation finance and the theory of investment. Amer. Econom. Rev. 48(3):261-297.

Moniz E (2014) Statement from Energy Secretary Ernest Moniz on the 2014 Solar Job Census. Press release, Solar Foundation, U.S. Department of Energy, Washington, DC.

Petruzzi NC, Dada M (1999) Pricing and the newsvendor problem: a review with extensions. Oper. Res. 47(2):183-194.

Rajagopalan S (1998) Capacity expansion and equipment replacement: a unified approach. Oper. Res. 46(6):846-857.

Reindorp M, Tanrisever F, Lange A (2018) Purchase order financing: credit, commitment, and supply chain consequences. Oper. Res. 66(5):1287-1303.

Tanrisever F, Cetinay H, Reindorp M, Fransoo J (2015) Reverse factoring for SME finance. Accessed March 5th, 2020, http://dx .doi.org/10.2139/ssrn.2183991.

Tanrisever F, Erzurumlu SS, Joglekar N (2012) Production, process investment and survival of debt-financed startups. Production Oper. Management 21(4):637-652.

Terwiesch C, Bohn RE (2001) Learning and process improvement during production ramp-up. Internat. J. Production Econom. 70(1):1-19.

Tunca TI, Zhu W (2018) Buyer intermediation in supplier finance. Management Sci. 64(12):5631-5650.

Van Mieghem JA (2003) Commissioned paper: capacity management, investment, and hedging: Review and recent developments. Manufacturing Service Oper. Management 5(4):269-302.

Van Mieghem JA, Allon G (2015) Operations Strategy: Principles and Practice, 2nd ed. (Dynamic Ideas, Belmont, MA).

Weiss D, Maher MW (2009) Operational hedging against adverse circumstances. J. Oper. Management 27(5):362-373.

Xu X, Birge JR (2006) Equity valuation, production, and financial planning: a stochastic programming approach. Naval Res. Logist. 53(7):641-655.

Yang SA, Birge JR (2018) Trade credit, risk sharing, and inventory financing portfolios. Management Sci. 64(8):3667-3689. 